\title{
The Multi-layered PP Analysis and the Prefix $a$ - in English
}

\author{
Akiko NAGANO* \\ Graduate School of Information Sciences, Tohoku University, Sendai 980-8579, Japan
}

Received October 22, 2013; final version accepted February 7, 2014

\begin{abstract}
This study presents a generative-linguistic analysis of the prefix $a$-in English morphology. Using Baker's (2003) theory of syntactic categories and Svenonius' (2006, 2010) multi-layered analysis of spatial PPs, I argue that locative $o n$-phrases underwent the process of grammaticalization to yield $a$-words in which the prefix $a$-realizes the category Pred. Denominal and de-adjectival $a$-words so formed triggered the emergence of a productive derivational pattern that produces stative predicates of the complex category Pred $+\mathrm{A}$ from inputs of any lexical category $(\mathrm{N}, \mathrm{A}$, and $\mathrm{V})$. This analysis accounts for the non-canonical syntactic distribution of $a$-words as well as their morphological left-headedness.
\end{abstract}

KEYWORDS: syntax-morphology interface, grammaticalization, Spatial PPs, the preposition on, the prefix a-

\section{Introduction}

This paper examines the historical development of the English prefix $a$ - from the perspective of the multi-layered analysis of spatial PP (Adpositional Phrase) (Cinque and Rizzi 2010). This prefix, which is usually classified as a derivational one, exhibits peculiar properties both morphologically and syntactically.

First, $a$ - is peculiar in light of the right-headed structural nature of English words (Marchand 1969, Kastovsky 1986). In accordance with the right-hand head rule (Williams 1981), English prefixes usually function as modifiers to the input, producing words of the same syntactic category and semantic type as the input (Nagano 2011, 2013a). For example, the negative prefix un- attaches to $\mathrm{N}, \mathrm{A}$, and $\mathrm{V}$ and produces $\mathrm{N}, \mathrm{A}$, and $\mathrm{V}$, respectively, with the negative meaning attached (e.g. un-Cola, unkind, undo). ${ }^{1}$ The prefix $a$-, however, determines the output properties; according to traditional descriptions (e.g. Jespersen 1942, Marchand 1969, Quirk et al. 1985, Namiki 1985), $a$ - attaches to N, A, and $\mathrm{V}$ and produces A (e.g. aboard, alive, asleep).

Next, $a$-adjectives exhibit defective or marked distribution in light of English syntax. Canonical English adjectives can be used both attributively and predicatively. Thus, in modification, they allow both direct and indirect modification (Sproat and Shih 1988). Significantly, their position with respect to the modified noun is the same in both types of modification (Cinque 2010a). Whether as a direct or indirect modifier, a canonical adjective modifies a noun in the prenominal position, hence the ambiguity of the adjective in an old friend, for example (Bolinger 1967: 4). Aadjectives, on the other hand, are defective in being used only predicatively and not allowing direct modification. In addition, when functioning as an indirect modifier, they occur in the post-nominal position (e.g. people aboard). ${ }^{2}$

In this paper, I will show that these and other properties of the prefix $a$ - are crucially related to the historical development of the preposition on. Although the historical connection between $a$ - and on itself is a well-established view, shared by traditional grammarians such as Jespersen (1942), Marchand (1969), and Quirk et al. (1985), historical linguists such as Kastovsky (1992) and Nevalainen (1999), corpus linguists such as Marcus (1998), and generative linguists such as Cinque (2010a), many details remain to be elucidated. The contribution of this paper lies in filling in some of the missing details, discussing (i) how the prefix developed from the preposition specifically, (ii) why a prefix so derived can exhibit such peculiar properties as described above, and (iii) whether (and in what way) the development can be viewed as a case of grammaticalization. Crucially, as we will see below, these questions can be fruitfully discussed if one adopts the multi-layered structural analysis of a spatial PP.

My discussion will proceed as follows. Section 2 will survey Baker (2003) and Svenonius (2006, 2010), and the relationship between the two theories will be clarified in section 3. Based on these two sections, section 4 and section 5 will inquire into the questions on $a$ - raised above. 


\section{Frameworks}

This section introduces theoretical frameworks adopted in this paper, Baker's (2003) parts-of-speech theory in section 2.1 and Svenonius' (2006, 2010) multi-layer analysis of a spatial PP in section 2.2.

\subsection{Baker's (2003) Theory of Syntactic Categories}

Baker (2003) is a generative linguistic analysis of the lexical categories, V, N, and A. With the major goal of defining lexical categories purely structurally, Baker avoids the semantic or functional linguistic approach using notions such as "action" or "property" or the traditional generative feature-based approach using $[ \pm \mathrm{N}, \pm \mathrm{V}]$. Instead, he defines $\mathrm{V}$, N, and A using only syntactic notions, as summarized below, and seriously pursues the cross-linguistic analytical possibility of these definitions. In Baker's view, V, N, and A are the only lexical categories; as we will discuss below, $\mathrm{P}$ is a functional category, and $\mathrm{Adv}$ is a type of A.

(1) a. V: $\mathrm{X}$ is a verb if and only if $\mathrm{X}$ is a lexical category and $\mathrm{X}$ has a specifier (Baker 2003: 23).

b. $\mathrm{N}$ : $\mathrm{X}$ is a noun if and only if $\mathrm{X}$ is a lexical category and $\mathrm{X}$ bears a referential index, expressed as an ordered pair of integers (Baker 2003: 95).

c. A: the elsewhere or default lexical category (neither $\mathrm{N}$ nor V) (Baker 2003: 21).

To put this simply, verbs are licensers of subjects, nouns are bearers of theta-roles, and adjectives are neither of these.

According to this view, verbs assign a theta-role to the subject generated in their specifier, but adjectives and nouns are not theta-role assigners in and of themselves. They need the support of the functional category Pred (Bowers 1993) to assign a theta-role. Thus, VP is structurally parallel not to AP or NP but to Pred $+\mathrm{AP} / \mathrm{NP}$, as the structures in (3) for the sentences in (2) illustrate:

(2) a. Chris hungers.

b. Chris *(is) hungry.

c. Chris *(is) a teacher.

(3) a.

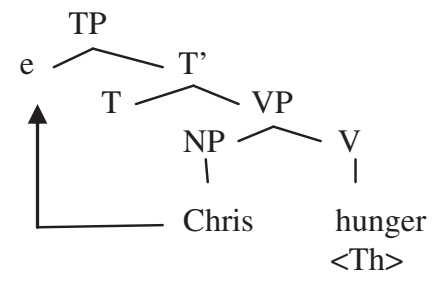

b.

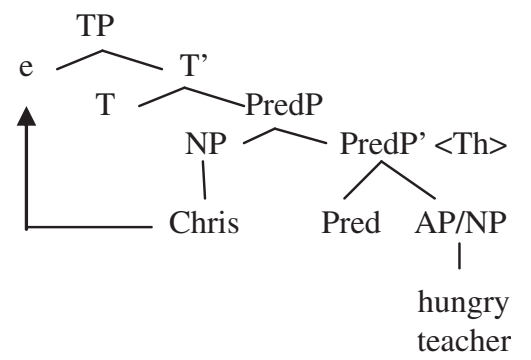

(Baker 2003: 35)

In fact, Baker (2003: sec. 2.9) decomposes V (unaccusative verbs) into Pred + AP. When A merges with Pred before vocabulary insertion, the A + Pred combination is realized as an unacussative verb, as in (3a). (3b), on the other hand, illustrates the case in which A is spelled out before the merge; Pred is separately spelled out as an appropriate vocabulary item, which is usually zero in English.

Also, Baker claims that the default character of A enables adjectives to occur in syntactic environments incompatible with the defining properties of nouns and verbs in $(1 \mathrm{a}, \mathrm{b})$. In particular, only adjectives can function as (i) direct modifiers, (ii) the complements of degree heads like so, as, too, and how, and (iii) resultative secondary predicates because they are neither theta-role bearers nor theta-role assigners. ${ }^{3}$ For example, in direct modification, the modifier merges with the head noun directly, with no functional structure mediating the relation:

(4) $[\mathrm{DP} \quad \mathrm{a} \quad[\mathrm{NP} \quad[\mathrm{A} \quad$ smart $] \quad[\mathrm{N}$ woman $]]]$

Nouns and verbs cannot be used in the modifier position (*a genius woman, ${ }^{*}$ a shine coin (Baker 2003: 191)) because it would leave the referential index of a noun and the theta-role of a verb unlicensed (Baker 2003: 195-200).

Baker takes $\mathrm{P}$ as a functional category. Observing that PPs can occur in the AP-specific syntactic environments identified above, attributive modification (5a), co-occurrence with degree heads (5b), and resultative construction (5c), he claims that $\mathrm{P}$ is a functional category that turns an NP into AP.

(5) a. a letter to/for Mary, chicken soup with rice 
b. John is too in love for his own good.

c. I cut the bread into slices. I smashed the vase to pieces.

We have seen that Baker analyzes Pred as a functional category that turns an AP into VP. In a similar vein, he analyzes $\mathrm{P}$ as an NP-to-AP category-shifting functional category. His view can succinctly be summarized as follows:

(6) a. V is equivalent to Pred $+\mathrm{AP}$.

b. A is equivalent to $\mathrm{P}+\mathrm{NP} / \mathrm{DP}$. (Nishiyama 2005: 151)

If the view in (6) is correct, Baker argues, there should be two types of functional categories, transparent type and opaque type. Transparent functional categories are those that form extended projections in the sense of Grimshaw (1991), functional categories which keep the inherent nature of the complement they select intact. For example, Tense does not change the category of $\mathrm{V}$, and Determiner does not affect the nature of $\mathrm{N}$. In contrast, opaque functional categories change the inherent nature of the lexical category they select, making it syntactically opaque. This type includes Pred, P, and also NP-producing functional categories such as the English nominalizer -ing.

Finally, as a summary of this section, I cite Baker's typology of syntactic categories below. ${ }^{4}$

(7)

\begin{tabular}{llll}
\hline & Lexical & Functional/Transparent & Functional/Opaque \\
\hline Licenses specifier & Verb & Aspect, Tense & Pred $_{\mathrm{N}}$, Pred $_{\mathrm{A}}$ \\
Bears Ref. Index & Noun & Det, Number, Case & -ing, (that ?, -ness?) \\
Neither & Adjective & Degree & Adposition \\
\hline
\end{tabular}

(Baker 2003: 325)

\subsection{Svenonius' (2006, 2010) Multi-layered Analysis of Spatial PPs}

The view that PPs that express spatial relations have a layered internal structure is not new. Jackendoff $(1987,1990)$, for example, provides the directional PP into the house with the internal structure in which the directional head to takes the locational phrase headed by in as its complement, i.e. [to [in [the house]]]. Recent research development in the cartographic approach to syntactic structures, however, has given rise to a wealth of detailed studies about spatial PPs in various languages (e.g. Cinque and Rizzi 2010), which have revealed the possibility of their having a much finer structural layering.

\subsubsection{Locational PP}

Svenonius (2006, 2010), for example, proposes that the locational phrase itself (e.g. in the house in the above example), which he calls PlaceP, has a multi-layered internal structure, built up by (at least) six different functional heads:

(8) PlaceP: $p$ - Deg - Deix - Loc - AxPart - K - DP

$\begin{array}{llllll}\text { a. } & \text { AT } & \text { in } & \text { front } & \text { of the car } \\ \text { b. } & \text { AT } & \text { there on } & \text { top } & \text { of the roof } \\ \text { c. } & \text { AT ten meters } & & \text { behind } & & \text { the house }\end{array}$

(Svenonius 2010: 144)

The term Place is a cover term for the collection of functional heads from $p$ to K. Semantically, Place specifies how space is projected from a region. Under the vector-based space semantics of locational PPs (Zwarts 1997), each head in (8) can be given an explicit semantic motivation.

To begin with the bottom, $\mathrm{K}$ in this decomposition is a function from a ground DP to a region. It is a kind of typeshifter, lifting the DP to a predicate. While Wunderlich (1991: 598) suggests that the K, his "eigenplace" function, is never expressed overtly, Svenonius (2010: 156, fn. 6) claims that genitive case in many languages is an overt expression of K. For instance, $\mathrm{K}$ is expressed by of in $(8 \mathrm{a}, \mathrm{b})$.

The eigenplace or region so derived is mapped to its subpart by AxPart, front in (8a) and top in (8b). AxPart words typically refer to the front, back, top, bottom, sides, and middle of an object. ${ }^{6}$

In the next step, the eigenplace or region of the ground DP is mapped into a vector space by Loc, the prepositions on and in in (8a, b) and zero in (8c). On and in are deemed particularly important members of the category Loc; "on specifies that there is contact, which implies that the vectors used to define the space have length zero, and in specifies that the space is bounded" (Svenonius 2006: 53).

Then, in a further step, Deg (for Degree), predominantly represented by measure expressions such as ten meters in (8c), identifies the ends of the vectors as a region; it is a function from vector spaces to the regions of space that the vectors pick out. 
In total, these steps mean that locative prepositions like in front of (8a), on top of (8b), and behind (8c) turn a region (the eigenplace of the ground) into a vector space and then back into a region (the set of points in which the figure is located).

In addition, Svenonius (2010: 133-136) claims that there is another head higher than Deg, $p$ in (8), considering that a locational PP is relational and a figure argument must be introduced. The category $p$ introduces a figure argument in neo-Davidsonian fashion, in a parallel manner to Kratzer's (1996) Voice head in the VP. This $p$ is the locus of relational meanings such as contact, containment, attachment, and support. For example, prepositions such as on, upon, and against share the meaning component of contact, while in names the relation of containment. Some of Svenonius's (2010: 128) "bounded prepositions," between and among for example, imply a more complex relation between a figure and a ground.

Although Svenonius does not mention it explicitly, it is clear from his discussion that $p$ in English is often morphologically covert. Following Collins (2007) and Cinque (2010b), I indicate the null $p$ as AT, the counterpart of the overt $p$ at. Svenonius also suggests that between and among are spelled out at $p$, given that these prepositions supply rich enough relational meanings to make them incompatible with a measure expression:

(9) a. We remained sixty feet in front of the palace.

b. *They came from six feet between the trees.

(Svenonius 2010: 135)

\subsubsection{Directional PP}

Jackendoff's view of a directional P governing a locational $\mathrm{P}$ seems to be inherited widely among recent studies on spatial PPs (e.g. Collins 2007, cf. Ayano 2005). Svenonius (2006, 2010: sec. 3) also follows this position, claiming that the direction-denoting in front of in (10a) has an internal structure like (11): ${ }^{7}$

(10) a. The boat drifted (?to) in front of the palace.

b. These electrons must be coming from at or near the surface of the crystal.

(Svenonius 2010: 130)

(Collins 2007: 7)

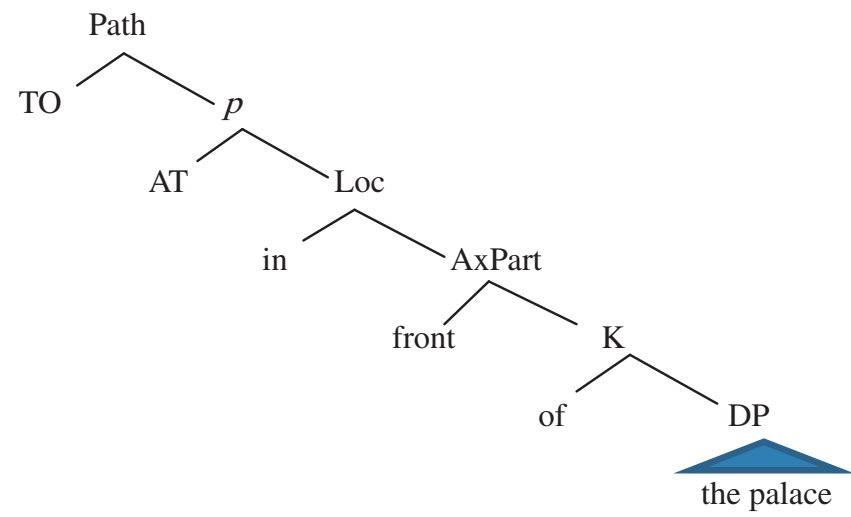

As in (10a), PlacePs can take on a directional or path-denoting meaning because English has a null form of the goaldenoting preposition to, i.e. TO in (11). As the parenthesis in (10a) implies, even the overt to is marginally licit in the same context. (10b) shows more explicitly the possibility of distinct morphological manifestations of a directional $\mathrm{P}$ and a locational $\mathrm{P}$.

Svenonius calls a directional PP PathP. Overt and covert to (Goal) and overt from (Source) are canonical Path heads in English. As in (11), the Path head always selects a PlaceP (see also Collins 2007: sec. 2). As in (10), the null to is licensed by verbs of motion (e.g. drift). ${ }^{8}$ Semantically, in a goal PathP, the complement PlaceP names the final point in a path of motion, while in a source PathP, the PlaceP names the initial point.

Finally, I will briefly summarize Svenonius' (2010: sec. 4) analysis of particles. In English, in, on, up, down, off, out, and away can function as particles. First, particles combine with a PlaceP (12a) or a PathP (12b). In the former case, particles do not restrict the space denoted by the locational PP; rather, they introduce viewpoint or "logophoric center" for the space. On the other hand, particles with a PathP restrict the Path denotations.

(12) a. I left my spear down between the floorboards.

(Svenonius 2010: 143)

b. The boat drifted down from above the dam.

(Svenonius 2010: 150)

Second, as in (13a), particles can express Path by themselves, without any overt PathP. In contrast, as shown in (13b), particles require an overt ground to express Place.

(13) a. The boat drifted down. 
b. Smell the well! I think there must be a dead opossum down *(it). (Svenonius 2010: 152)

Overall, these properties indicate that particles are close to Path heads, though their relation to PlaceP is different from the relation of Path selecting Place. Svenonius suggests that particles in cases like (12a) are adjoined to the $p$ level, which is confirmed by the fact that down precedes between in (12a); between is spelled out at $p$ (section 2.2.1).

\section{Two Types of $\mathbf{P}^{9}$}

The aim of this section is to make a fruitful connection between the two theories introduced in section 2 by expanding on Nishiyama (2005).

\subsection{Nishiyama (2005)}

Baker defines P as the NP-to-AP category-shifting functional category, as discussed in (6b). Nishiyama (2005), a review article on Baker (2003), objects to this definition and advances the following alternative:

(14) P is equivalent to Pred.

(Nishiyama 2005: 144)

Nishiyama arrives at this definition based on (among others) the behaviors of the Japanese postpositions de "at" and $n i$ "in(to)." The Pred status of these postpositions is most explicitly seen in the fact that they select not only an NP complement, as in (15), but also an AP complement, as in (16). ${ }^{10}$

(15) a. $\mathrm{NP}+d e$

hon-ga moe-ta $\quad<$ PlaceP $>$

book-Nom garden-loc burn-Past

"The book burnt (in the garden)."

b. $\mathrm{NP}+n i$

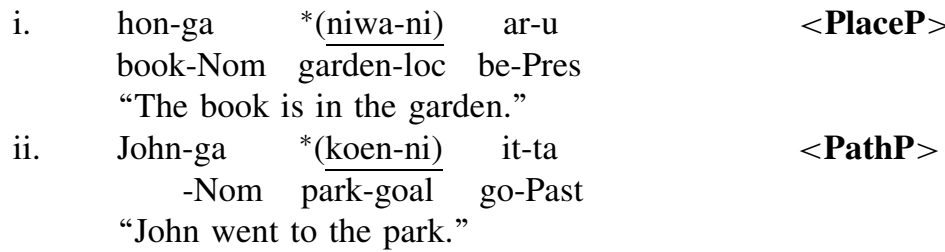

(16) a. $\mathrm{AP}+d e$

$$
\begin{aligned}
& \text { John-ga sakana-o }(\text { nama-de) } \\
& \text {-Nom fish-Acc } \begin{array}{l}
\text { raw-Pred } \\
\text { eat-Past }
\end{array} \\
& \text { "John ate the fish (raw)." }
\end{aligned}
$$

b. $\mathrm{AP}+n i$

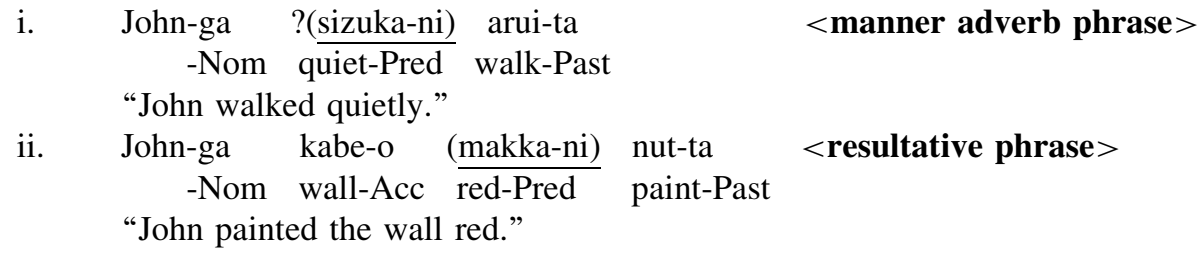

The sentences in (15) show that in the spatial domain, de forms the adjunct PlaceP of a dynamic verb (15a), while $n i$ forms the complement PlaceP of a stative verb (15bi), meaning "in," or the complement PathP of a directed motion verb (15bii), meaning "into." The sentences in (16) show that in a secondary predicate phrase, de is used for a depictive (16a), while $n i$ is used for a resultative (16bii). Also, $n i$ is used for a manner adverb (16bi).

Based on the considerations to be noted shortly, I summarize the $d e / n i$ alternation observed by Nishiyama as follows:
a. AT <adjunct $>$ $<$ complement $>$
b. $\quad$ TO $<$ complement $>$

\section{Spatial PP}

niwa-de "in garden" niwa-ni "in garden"

koen-ni "into park"
a'. <depictive $>$
$<$ manner $>$
b'. <resultative $>$

\section{Predicative Phrase}

nama-de "at raw state"

sizuka-ni "in a quiet way"

makka-ni "into red state"

As a crucial fact, English and Japanese morphologically realize a spatial PP based on different structural criteria. As discussed in section 2.2, the most basic morphological distinction in English spatial PP lies in the PlaceP vs. PathP 
distinction. In the English glosses in $(17 \mathrm{a}, \mathrm{b}), \mathrm{P}$ is distinguished at the AT vs. TO level. When a PlaceP appears to be used as a PathP, as in (10a), there is a covert Path preposition TO dominating it. (10b) explicitly shows that English realizes the Path head and the Place head AT by means of different prepositions. In contrast, this language does not morphologically distinguish a complement PlaceP from an adjunct one, as shown by the English translations of (15a) and (15bi).

The Japanese postpositions $d e$ and $n i$, on the other hand, embody the adjunct vs. complement distinction of a spatial PP. As (17) indicates, $n i$-PP can be used both as a PlaceP and a PathP as long as it is a complement to the (main) predicate. An adjunct PlaceP, on the other hand, is realized by de. Given Collins' (2007: sec. 7) conclusion (on English spatial PPs) in (18), $n i$ and de should be viewed as allomorphs of AT (cf. Noonan 2010); the AT-phrase is realized by $n i$ when it occurs as a complement to a verb and by de otherwise.

(18) A PathP headed by "to" (covert or overt) is always the complement of a verb. A PlaceP headed by AT, on the other hand, can be the adjunct or complement to a verb. ${ }^{11}$

The $n i$-PP is locational when selected by a stative predicate and directional when selected by a telic dynamic predicate (Ogawa and Niinuma 2013). According to Ogawa and Niinuma (2013), the ni-PathP is licensed not by a covert TO but by AspP, an aspectual functional head situated above VP, with the value [+telic]. This analysis is based on the observation that when occurring with a dynamic predicate, a ni-PP, but not a $d e$ - $\mathrm{PP}$, contributes to the telicity of the entire event:
a. Niwa-ni/de kosumosu-ga saita
garden-NI/-DE cosmos-Nom bloomed
"Flowers of cosmos bloomed in the garden."
b. Niwa-zentai-ni/*de is-shuukan-de kosumos-ga saita garden-entire-NI/-DE one-week-in cosmos-Nom bloomed "Flowers of the cosmos I planted bloomed in the garden in a week."

(Ogawa and Niinuma 2013: 232-233)

Ogawa and Niinuma's analysis enables us to dispense with the independent covert morpheme TO in Japanese. As predicted, the ni-PP cannot be directional with a manner-of-motion verb; as in (20a) below, the literal Japanese translation of (10) via a $n i$-PP is grammatically incorrect.

(20) a. *Booto-ga kyuuden-no-mae-ni tadayotta

Boat-Nom palace-Gen-front-loc drifted

b. Booto-ga kyuuden-no-mae-ni tadayotte-itta

boat-Nom palace-Gen-front-loc drift-went

"The boat drifted in front of the palace."

Following Noonan (2009), I assume that Japanese TO is conflated in inherently telic directed motion verbs such as $i k u$ "go." Manner-of-motion verbs such as tadayou "drift" can acquire the directional telic interpretation by incorporating TO in the form of a compound verb, as indicated in (20b).

In sum, the Japanese counterpart of the structure in (11) would be like as follows. When the Path head is TO, a bounded Path head, it is conflated or incorporated into a verb. The Place head AT is realized either by $n i$ or de depending on the syntactic position of the PlaceP. ${ }^{12,13}$

We have seen that Japanese crucially differs from English in its sensitivity to the complement vs. adjunct status of a spatial PP. Importantly, the morphological realization of AP in (16) duplicates this sensitivity. Although English does not morphologically distinguish depictive and resultative APs, Japanese mark them differently, using de for the depictive AP (16a) and $n i$ for the resultative AP (16bii). According to the standard view (e.g. Rothstein 1983, McNulty 1988, Baker 2003: sec. 4.4.1), resultative phrases are more tightly integrated into the VP than depictive phrases are, the former being selected by the verb while the latter adjoined to the VP. Ogawa and Niinuma (2013) show that the resultative $n i$-phrase in (16bii) is licensed in the same manner as the $n i$-PathP in (15bii), by the movement from the complement position of the res event head (the Result subevent head; Ramchand 2008) up to the specifier of the Asp [+telic] head. The de-depictive, on the other hand, is analyzed as an adjunct to a dynamic predicate (Ogawa and Niinuma 2013: sec. 2.2).

As for manner adverbial phrases such as (16bi), I assume that a manner phrase is also marked by $n i$ because it occurs in the complement (Rheme/Path) position of the proc (Process) event head in Ramchand's (2008) framework. Notice that while the depictive phrase in (16a) is completely optional in the sense that its presence/absence does not affect the grammaticality of the sentence, removing the underlined manner phrase from (16bi) makes this sentence sound a little awkward. Without it, the predication sounds informationally incomplete. In other words, the manner phrase adds necessary information to the verb aruita 'walked' in the predication of the subject. In Ramchand's framework, this type 
of syntactic element is called Rheme and captured by the head-complement relationship (with respect to an event head). Rheme can be NP, AP, and PP; in the following sentence, the verb aruku takes an NP rheme:

(21) John-ga ?(yamamichi-o) arui-ta

-Nom mountain path-Acc walk-Past

"John walked along a mountain path."

\subsection{Spatial PPs and Non-verbal Predicative Phrases}

Returning to Nishiyama's arguments, I agree with him that the de/ni alternation in (17) strongly suggest that these postpositions function as Pred, illustrating the definition in (14). However, I do not think that this fact speaks against Baker's analysis of P in (6b). Rather, I submit that Baker's and Nishiyama's definitions of P focus on different facets of $\mathrm{P}$, i.e. different functional heads of the multi-layered internal structure of a spatial PP. ${ }^{14}$ More specifically, I propose the following correspondences:

(22) a. P as category-shifter $(6 \mathrm{~b})=\mathrm{K}$ of the PlaceP

b. $\quad$ P as Pred $(14)=p$ of the PlaceP

The correspondences in (22) have both theoretical and empirical support. First, they are confirmed by Svenonius' semantic descriptions of the functional heads $\mathrm{K}$ and $p$ discussed in section 2.2.1. He defines $\mathrm{K}$ as a type-shifter that lifts the ground NP to a predicate and $p$ as the introducer of a figure argument, respectively. These definitions neatly match Baker's definitions of P and Pred; as discussed in section 2.1, he uses P as the NP-to-AP category-shifter and Pred as the licenser of the external argument for AP and NP.

Second, if (22) is correct, the multi-layered structure of PlaceP in (8) explains why Pred can combine with both NP and AP, as observed in (15) and (16). In (8), K shifts the ground DP/NP into AP. Hence, $p$ or Pred naturally selects AP. The present view of [K [DP]] in (8) as an equivalent to AP is corroborated by its being selected by the Deg head; as shown in (7), Deg is an extended projection of the category A. In addition, K often lacks formal realization (see section 2.2.1 for Wunderlich's and Svenonius' views on the morphology of K). In (8), when K does not surface phonetically, $p$ or Pred appears to combine with DP (or NP). In a word, if (22) is correct, one can capture the parallelism between nonverbal predicative phrases and spatial PPs observed in (17), as follows:

(23) a. $[$ PredP Pred $[\mathrm{AP} / \mathrm{NP}]]$ is equivalent to

b. [PlaceP $p \quad[$ AP K $[\mathrm{NP}]]]$

(22) and (23) receive empirical support from the cross-linguistically prevalent distinction of two types of modification, direct and indirect modification (Cinque 2010a). As discussed in (4), a direct modifier is an AP without Pred. Then, if (23) is correct, the embedded component of (23b), [K [NP]], should be able to function as a direct modifier. On the other hand, the entire structure of (23b), [ $p$ [K [NP]]], should be illicit as a direct modifier; it functions only as an indirect modifier. These predictions seem to be empirically correct:

\begin{tabular}{|c|c|}
\hline a. & $\begin{array}{l}\text { *niwa-de-no } \\
\text { garden-loc-Mod flower } \\
\text { "(intended as) flowers in the garde }\end{array}$ \\
\hline b. & $\begin{array}{l}\text { niwa-no } \\
\text { garden-Gen flowers } \\
\text { (i) "garden flowers" } \\
\text { (ii) "ffowers that are in }\end{array}$ \\
\hline
\end{tabular}

\section{a'. niwa- $\left\{\mathrm{de} /{ }^{*}\right.$ ni $\}$-no (kosumosu-no) kaika

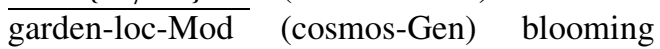 "the blooming (of a cosmos) in the garden"}

b'. $\quad \frac{\text { niwa-no }}{\text { garden-Gen }} \begin{aligned} & \text { kosmosu } \\ & \text { cosmos }\end{aligned}$

(i) * "garden cosmoses"

(ii) "cosmoses that are in the garden"

((24a') taken from Ogawa and Niinuma (2013: 235) with modifications)

In (17), we saw that the PP niwa-de "in the garden" is a PredP adjoined to a dynamic event. As predicted, the contrast between (24a) and (24a') suggests that this phrase can indirectly modify a noun that has an event argument (or e-place); according to Ogawa (2001), event nominals, IAP (inalienable possession) nominals, and relational nominals are stage-level predicates with an e-place. I assume that the $d e$-PredP in (24a') is predicated of this e-place. In contrast, the PredP in (24a') cannot be realized by $n i$ because the event nominal kaika does not project up to AspP (Ogawa and Niinuma 2013: 243-244). ${ }^{15}$

Next, the underlined no-phrase in (24b) has two distinct interpretations, (i) "garden flowers" (which contrast with e.g. yasei-no hana lit. wild-K flower "wild flowers") and (ii) "flowers that are in the garden." As suggested in (24b'), only in the latter interpretation, the head nominal hana "flower" can be freely replaced with subtype names of flowers. These interpretations suggest that niwa-no in (24b) can be either a direct modifier, yielding the interpretation in (i), or a 
genitive NP, yielding the interpretation in (ii) (for the semantic characteristics of direct modification, see Cinque 2010a: sec. 1). As predicted, only under the (ii) interpretation, niwa in (24b) can be restricted by a D element or by a modifier (e.g. tonari-no niwa-no hana 'lit. next-door-Gen garden-Gen flowers,' "flowers that are in the next door's garden"), and can be separated from the head nominal by another modifier (e.g. niwa-no kirei-na hana 'lit. garden-Gen beautiful-Pred flower,' "beautiful flowers in the garden"). These expansions are always possible with the no-phrase in (24b'). The most plausible account for the (i) reading is that the genitive no in (24 bi) is K and turns the NP niwa "garden" into an (element close to) AP, as shown in (25a). For comparison, I show the structure of the indirect modifier in (24a') in (25b).

(25) a. niwa-no in (i) [[niwa $]$ no $]_{\mathrm{AP}}$

b. niwa-de [[[niwa] $\mathrm{K}]$ de $]$ PlaceP/PredP

Significantly, the depictive phrase nama-de "raw, at raw state" in (16a) occurs in the same nominal modification pattern as (24b); it can modify only a nominal with an e-place, as in (26a, a'). On the other hand, the no-form nama-no "raw" is ambiguous between the two structures in (25), or between the functions as direct and indirect modifiers. Just like the English adjective raw, nama-no can be either a direct modifier, as in (26b i), or an indirect modifier, as in (26b ii).

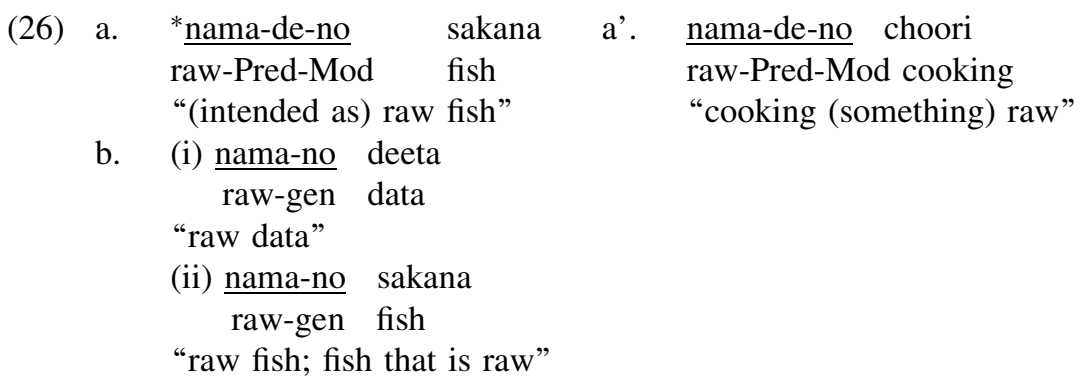

The status of the genitive no as K is confirmed by Svenonius' (2010: 156, fn. 6) claim that genitive case in many languages can be an overt expression of K. In addition, it is independently confirmed by Watanabe's (2012) observation that material/nationality-denoting direct modifiers take the "N-no" form in Japanese, as in (27a', b'), in contrast to the denominal or relational adjectival form used in English $(27 \mathrm{a}, \mathrm{b})$.

(27) a. wooden desk

$$
\begin{aligned}
& \text { a'. ki-no tsukue } \\
& \text { wood-Gen desk } \\
& \text { "wooden desk" } \\
& \text { b. Chinese vase b'. Chuugoku-no kabin } \\
& \text { China-Gen vase }
\end{aligned}
$$

In Nagano (2013b), I showed that relational adjectives are morphological realizations of the embedded structure [K [NP]] in (23b). The "N-no" form, on the other hand, is a syntactic realization of the same structure (Nagano and Shimada 2013).

Turning to English data, in section 2.2, we saw that the English $p$ is often morphologically covert AT (see also Nishiyama 2005: 150), and the prepositions in and on occur in the head Loc. Then, if (23) is correct, the in-PlaceP should form an indirect modifier with the following internal structure:

$$
\text { [PredP AT [LocP in }[\mathrm{K} \quad[\mathrm{NP}]]]
$$

As a result, unlike (24b), the modification by in the garden cannot have a direct modification reading. Yet, at the same time, the indirect modification by the in-PlaceP is not restricted to the head nominal with an e-place; it can modify a sortal noun in a parallel manner to the genitive-marked nominal in Japanese:

(29) a. (the) blooming in the garden

cf. (24a')

b. flowers in the garden

cf. (24a) (24bii)

The PlaceP/PredP in the garden is predicated of the e-place of blooming in (29a), while it is predicated of flowers in the specifier position of the PredP.

Also, since the $p$ or Pred in English is usually null, predicative AP phrases occur in a "bare" form, with no prepositional element, unlike the Japanese depictive and resultative phrases in (16a, b): 
(30) a. John ate the fish raw.

(the counterpart of (16a)) <depictive phrase $>$

b. John painted the wall (*into) very red. (the counterpart of (16bii)) <resulative phrase $>$

The discussions on section 3.1 indicate that the depictive phrase in (30a) and the resultative phrase in (30b) have the internal structures like (31a) and (32b) below, respectively:

(31) a. [PredP AT [AP raw ]]

b. [PathP TO [PredP AT [Deg very [AP red ]]]

Although the unavailability of into in (30b) shows that the goal preposition TO is not phonetically realized in (31b), the resultative phrases in $(5 c)$, repeated below as $(32 a)$, show that it can. (32b) indicates the internal structure of the first resultative phrase in (32a).

(32) a. I cut the bread into slices. I smashed the vase to pieces. $\quad(=(5 \mathrm{c}))$

b. [PathP to [PredP AT [Loc in [ K [ slices ]]]

To sum up, sections 3.1 and 3.2 have clarified the strong linkage between Baker's (2003) P and Pred and Svenonius' (2006, 2010) multi-layer analysis of spatial PPs. The Japanese postpositions $n i$ and de are Pred, occurring in the $p$ position in the multi-layer PlaceP structure in (8), while the English prepositions in and on are not Pred but rather close to $\mathrm{P}$, occurring in a lower position than $p$.

\section{The Development of $a$ - from on}

Using the relationship between spatial PP and non-verbal predicative phrases established in section 3 , this section attempts to make a formal analysis of the historical development of the prefix $a$ - from the preposition on. Put very simply, my hypothesis is that this development embodies a diachronic version of Baker's (2003) conception of the synchronic relationship between the lexical categories $\mathrm{A}$ and $\mathrm{V}$, repeated below from $(6 \mathrm{a}, \mathrm{b})$ :

(33) a. A is equivalent to $\mathrm{P}+\mathrm{NP} / \mathrm{DP} . \quad(=(6 \mathrm{~b}))$

b. $\quad \mathrm{V}$ is equivalent to Pred $+\mathrm{AP} . \quad(=(6 \mathrm{a}))$

The source locative preposition on is basically $\mathrm{P}$ in (33a), if the finer distinction between $\mathrm{K}$ and Loc is ignored, and basically functions as an $\mathrm{A}(\mathrm{P})$-forming element. On the other hand, the prefix $a$ - embodies Pred, like the Japanese postpositions $d e$ - and $n i$-, and produces words of the status [Pred $+\mathrm{AP}]$.

\subsection{Formal Change}

As I mentioned in section 1, many researchers argue that the prefix $a$ - originated from the preposition on. Curiously, however, as far as the studies I have consulted are concerned, none of them discuss whether this development is an instance of grammaticalization or not. This question is directly connected to the question of why or by what mechanism a preposition can change into a derivational affix.

Prototypically, grammaticalization is viewed as a diachronic process characterized by a unidirectional shift of category and form (Traugott 2010: sec. 2). Categorially, an item of a lexical category changes into an item of a functional category (a stage called Primary grammaticalization), and also an item of a "less" functional category changes into an item of a "more" functional category (a stage called Secondary grammaticalization). Formally, a free morpheme gradually loses syntactic independency and undergoes phonetic reduction, changing first into a bound morpheme and then into zero. These unidirectional changes of category and form due to grammaticalization are depicted most explicitly in the following "cline of grammaticality" by Hopper and Traugott (2003):

(34) content item $>$ grammatical word $>$ clitic $>$ inflectional affix

(Hopper and Traugott 2003: 7)

In addition to this traditional view, some researchers advocate incorporating the following sort of semantic extensions into the unidirectionality of grammaticalization:

$$
\text { person }>\text { object }>\text { activity }>\text { space }>\text { time }>\text { quality }
$$

(Heine, Claudi and Hünnemeyer 1991: 48)

Below, based on the changes of form and category, I will argue that the mechanism underlying the change from on to $a$ is grammaricalization. Also, I will briefly discuss the view in (35) in light of the $a$-data.

Let us start with the formal change from on to $a$-. The most important formal stages are the three depicted below, the preposition on stage, the clitic $a$ stage, and the prefix $a$-stage: 
(36) a. [on DP]: on his horse back, on her feet

b. [a DP/NP]: a horseback, a foote, a-mornings

c. [a-N/A/V]: afield, anew, atwitter

According to the Oxford English Dictionary (OED henceforth) ${ }_{16}^{16}$ its entries of $<o n$, prep. $>,<a$, prep $^{1}>$, and $<a-$, prefix $^{3}>$ to be specific, the PlaceP by the preposition on in (36a) gave rise to the structure in (36b) before 1200 because "unstressed $o n$ before a consonant was worn down to $o$ or $a$." Since then, (36b) seems to have had been used side by side with (36a) until "the separate preposition $a$ ceased to be used in standard English after about 1700, being replaced by the full on, in, or the various prepositions which represent them in modern idiom [...]" In the meanwhile, as early as in OE (Old English) and EME (Early Middle English), "compound adverbs" of the structure in (36c) were derived from the prepositional phrases in (36a) and (36b); subsequently, (36c) developed into a productive derivational process by the prefix $a$-.

The diachronic relationships among (36a-c) indicated above, i.e., (36a) having developed into (36b), and (36a, b) into (36c), are also suggested by the gradual reduction of the bracketed structure from a full-fledged phrase to a smaller phrase and finally into a word.

First, the source construction, the stage (36a), is a full-fledged phrase with a free-standing preposition. The quotation data in $O E D$ show that the preposition on takes a DP complement, whose head is predominantly an entity nominal, as in (37a). It does not take a VP or AP directly as its complement; when the head of the complement seems to be a verb or adjective, it is a zero-derived noun, as in (37b); zero-derived nouns are typically entity or result nouns (Ito and Sugioka 2002: ch.3). Since OE, on takes a deverbal noun in -ing (-ung in OE), as illustrated in (37c), forming the source constructions of (i) the be Ving progressive construction (Visser 1966: 1996-2004, Nakao 1972: 260) and (ii) the go/ come Ving purpose construction (Zandvoort 1969: 43). ${ }^{17}$ According to Tajima (1985) and Koma (1998, 2000), the deverbal -ing noun was also originally a result or entity nominal, acquiring the argument-structure property of a complex event nominal gradually in ME and ModE (Modern English).

(37) a. 1375 Sche wold...Meke hire in his merci on pise maner wise.

1656 He sat a long time on his horse back in a profound study.

b. a1400 All on-slepe he fand pam fast.

1451 I lay on wayte vp-on hym.

1939 He put up a row of villas and in a short while let them all on lease.

1998 I'm on night shift and I've got to rush.

c. (i) be on Ving

c1300 Hit was in one someres day...pat...pe gode kinge Rod on his pleyhinge.

1387 While pe gospel was on redynge.

a1500 Whyle Torrent an huntyng wase.

(ii) go on Ving

1300 pis child scholde wende An hontingue.

1622 That might. ...set the Plough on going.

Next, in the stage (36b), the prepositional element still maintains syntactic independency, but its form is reduced to $a$, which cannot bear stress and is pronounced as a schwa. In light of the importance of phonetic change as a criterion of grammaticalization, I view this phonological reduction as the strongest piece of evidence for setting the stage (36b) apart from the stage (36a). Syntactically, the $a$ in (36b) differs from the full form on in taking DP or NP headed by (complex) event nominal as its complement; the relevant examples are found in (38a) and (38d). As stated above, on takes entity or result nominals as its complement. Notice that the Ving-s of the progressive and purpose constructions in (37c) do not have an argument or adjunct, unlike those in (38d). Because there are examples such as (38b, c), it is not the case that the reduced $a$ always take an event nominal complement, but it seems safe to say that the syntactic change of the Ving form mentioned above correlates with the phonetic change of $\mathrm{P}$ from on to $a$.

(38) a. 1482 Whyll I am a whryttyng of thys letter.

1523 They are all a horsbacke.

1523 The queen was brought a bedde of a fyre lady named Margarete.

b. a foote, a-wheels, a-mornings, a-nights, a-whiles, a-night-times, a-pieces

c. a-this-half

1616 Why dooest thou garter vp thy armes a this fashion?

1848 I don't think every one would grieve a that way.

d. (i) be a Ving

1523 They had ben a fyghtyng with theyr enemies.

1627 His enyme... that was a preparing to invade his countrys.

1842 An old widower that's ben a-marrying of a young girl. 
(ii) go a Ving

1673 Set it a boiling in a clean soured Skillet.

1780 I., Went an eeling. \{in the river/*to the river\}

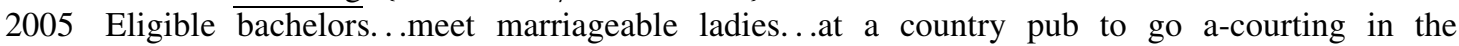
Cotswolds.

Note that the prepositional element $a$ is connected to the complement by a hyphen in some instances in (38). I take this hyphen as a maker of the clitic status of $a$, just like the apostrophe preceding $s$ in the possessive phrase. ${ }^{18}$ Being a clitic, $a$ in this stage can attach to plural forms, as in (38b), and scopes over not only the hyphenated noun but the NP as a whole. For example, in (38a), a scopes over or takes as its complement not only its phonological host writing but also the whole NP (writing of this letter). The same is true of (38d). In (38d ii), for example, the complement of $a$ is not only Ving (eeling) but also the whole phrase it projects (eeling in the river); therefore, the preposition after Ving should be a locative one. If it were selected by the main motion verb, it should be a directional preposition like to (Nagano 2008: sec. 5.4.3). Also of importance here is the fact that English affixes, derivational or inflectional, are not separated from their bases by a hyphen, except for the purpose of emphasis. Hence, the usage of the hyphen in the stage (36b) does not mean that $a$ has attained the status of an affix; when it really has, it is directly bound to its base, as in the next stage in (36c).

The third stage, depicted in (36c), is clearly distinguished from the preceding two stages in three formal properties: (i) the boundness of the prepositional element, (ii) the syntactic category of its complement, and (iii) the size of the entire construction. First, as is indicated by the hyphen-less direct attachment, $a$ in this stage differs from the one in the stage (36b) in surfacing as a bona-fide English prefix. As for the second and third differences, whereas in (36a, b) $\mathrm{P}$ takes a DP or NP complement and produces a PP, in (36c) it takes a nominal, adjectival, and verbal complement in an uninflected form and produces a word. The $a$ in (36c) scopes over its phonological host only. According to Lehmann (1985: 306), the reduction of scope is one parameter that indicates the degree of grammaticalization, the scope of a grammaticalized element being restricted to its immediately following element. ${ }^{19}$

The three distinguishing properties of the stage (36c) can be seen in the following data of $a$-words recorded in the $O E D$. In total, I have collected 327 a-prefixed words from the $O E D .181$ of them (approximately 55\%) are denominal, 38 thereof (approximately 12\%) are de-adjectival, and 88 thereof (approximately 27\%) are deverbal. The remaining 20 consist of $a$-words with a parasynthetic structure (15 instances), those from a preposition ( 2 instances), and those of obscure base ( 3 instances). In (39a-c), I cite representative examples from each base category, classifying them according to broad semantic types. The underlined examples in (39a) are $a$-words which are etymologically denominal but later come to be recognized as deverbal (see the discussion in section 5.1).

\section{(39) The data set of $327 a$-prefixed words from the $O E D$}

\section{a. $[\mathrm{a}+\mathrm{N}]: 181$ tokens (approximately $55 \%$ )}

(i) location abed, a-room, aside, a-root, aboard, aplace, a-shore, a-port, afield, aground, aland, alee, aroom, aside, ahorseback, a-shelf, a-peak, a-shipboard, astern, abox, a-sea, awheel

(ii) time aday, a-night, a-noon, a-week, a-morning, a-morrow

(ii) state afire, agrief, ajar, alight, arank, arow, athrong, aflame, aheight, ajoint, atop, adust, aheap, apart, apiece, abloom, ajar, aslope, alight, aline, a-rake, afoam, aheat, ablaze, asleep, aswoon, awane, awork, abroach, aslant, ahunt, astrain, aroar, atilt, afloat, adream, ahold, astrut

(vi) manner afoot, abrood, atiptoe, a-wing, apace, aslug "sluggishly," acrook "crookedly," acock

(iii) goal aboard, afield, aground, alee, aside, aheight, awest, anorth, adistance, aloof

\section{b. $[\mathrm{a}+\mathrm{A}]: 38$ tokens (approximately $12 \%$ )}

(i) state

(ii) manner

(iii) goal alank, abroad, acold, aflat, aloud, awry, adeep, ahungry, aloose, ahigh, alow, afresh, anew, afar, afoul, alive, anear, anigh, alone, alike, adry, acoy

abroad, aflat "flatly," aloud, awrong "wrongly," awry "improperly," a-good, asudden "suddenly," adeep "deeply," afresh, anew, aright "rightly," awide abroad, aleft, aright, awry, afar, ahigh, afar, afoul, anear 


\section{c. $[\mathrm{a}+\mathrm{V}]: \mathbf{8 8}$ tokens (approximately 27\%)}

(i) state

agaze "gazing," acry "crying," aflaunt "in a flaunting state," ajar "in a jarring state," agape, asoak, astoop, astride, aswim "swimming," asquat, astraddle, abask, adance, adangle, aflicker, aflower "blooming," aweary "tired," awrack "in a state of wreck," atwist "twisted," atwitter, astray, awash, aswarm, a-shine, a-shiver, a-sparkle, a-wave

(ii) manner askew "obliquely," a-pluck "pluckily," agoggle "in a goggling fashion," agape, aglow

\section{d. $a$-words of the parasynthetic structure or other base category: 20 tokens}

The formal changes surveyed above strongly suggest that the development of $a$ - from on is an example of grammaticalization because they neatly follow the grammaticalization cline in (34), the grammatical word on turning into the clitic $a$ and further into the affix $a$-. The phrase-word relationship in this case is not a synchronic one, in which a word is derived from a phrase through head movement, as in the case of incorporation (Baker 1988), or alternatively, a word and a phrase constitute different realizations of the same underlying representation (Ackema and Neeleman 2004). For one thing, the existence of the intermediate stage, i.e. the clitic stage, testifies that on-phrases and $a$-words are related diachronically. For another, a synchronic phrase-word relationship basically observes the Mirror Principle (Baker 1985); for example, relational adjectives such as (27a, b) morphologically realize the underlying structure [K $[\mathrm{NP}]]$ in a mirror-image morpheme order relative to the phrasal realization (see Nagano 2013b for details). A-words, on the other hand, exhibit the same left-headed word order as on-phrases. This fact can be explained if they are related via grammaticalization, on-phrases gradually shrinking into words.

In the next section, I will show that the development of $a$ - can be seen as an instance of grammaticalization in terms of the categorial change.

\subsection{Categorial Change}

Categorially, the development of $a$-from on belongs to Secondary grammaticalization in which a functional item turns into a "more functional" item. One generative-linguistic interpretation of the degree of functionality implied in this definition is that it refers to the case in which an item of a functional category comes to be used as an item of a higher functional category (Roberts and Roussou 2003). For example, the grammaticalization of an adposition can be explicitly defined by means of a multi-layered PP structure like (8) and (11) as the upward change of the functional head it spells out. My hypothesis about the case at hand is:

(40) Categorially, the development from on to $a$ - represents a change from Loc to $p /$ Pred.

In section 2.2.2, we saw that the preposition on spells out the head Loc in (8). (40) means that due to the process of grammaticalization, it has come to be used as the spell-out of the higher head $p$.

In the history of English, some prepositions underwent a change equivalent to (40). Yokogoshi (2005), for example, shows that from ME to PE (Present-day English), as in a small clause underwent the change of its category from a "preposition," possibly a Loc-like element in (8), to a Pred element. In PE, as takes an NP, AP, or VP as its complement in a small clause, as in (41a-c). According to Yokogoshi, in ME and EModE, it allowed only NP complements, producing sentences equivalent to (41a), but in the eighteenth century, it started to allow AP complements also, producing sentences equivalent to (41b).

(41) a. They considered Mary as a fool.

b. They regard Mary as smart.

c. They regarded the book as given to Mary.

(Yokogoshi 2005: 85)

In this case, the preposition changed its category with its form intact. In our case in (40), in contrast, a preposition changed its category along with its form.

The first and clearest piece of evidence for the hypothesis in (40) has already been presented in section 4.1, the fact that while the preposition on and the clitic $a$ allow only a DP or NP as their complement, the prefix $a$ - can take an N, A, or $\mathrm{V}$ as its complement (the data given in (39)). As discussed in section 3 (see (23) in particular), $p /$ Pred, the highest head of the PlaceP, can take an NP or AP complement. Then, the selectional difference means that the preposition and the clitic are of the category Loc, while the prefix belongs to the category $p /$ Pred.

Second, if (40) is correct, $a$-words are morphological realizations of the structure $[p /$ Pred $[\mathrm{X}]]$. This explains why $a$-words cannot function as direct modifiers, a fact mentioned in section 1 and illustrated below. As discussed in section 2.1, direct modification does not involve Pred. 
(42) a. *the aboard people

b. * the abloom park

c. *an asleep man a'. the people aboard

b'. a park abloom with roses

c'. a man asleep

Baker (2003: 209) himself suggests that the contrast in (42) is attributable to a semantic factor, but such a view would raise a question of why a semantically similar participial adjective can function as a direct modifier:
a. *a asleep man $(=(42 \mathrm{c})$
vs. a sleeping man
b. *an alive language
vs. a living language

Under the hypothesis in (40), (43) represents a contrast between canonical adjectives in English, A in Baker's typology, and adjectives conflating Pred, i.e. [Pred+A].

Thirdly, unlike canonical adjectives, $a$-words cannot occur with degree words how, too, so, and as:

(44) a. The mouse is too *(much/far) alive/asleep/adrift/aglow.

a'. The mouse is too (*much) happy/revolting/brown.

b. The mouse is as *(much) alive/asleep/adrift as not.

b'. The mouse is as (*much) happy as he is brown.

(Beard 1995: 290)

Given (40), this property is also predicted from Baker's (2003) theory, according to which only As can have their grade specified by the dedicated functional head Deg. Notice that in the PlaceP structure in (8), the Deg head comes below the $p$ or Pred head and above the K head. Technically, Baker (2003: 213-218) uses this positional difference relative to Deg to account for why A but not [Pred+A/N] can have the grade licensed by Deg. Non-A items need the dummy much to support a Deg word. The same account applies to the contrast between (42a, b) and (42a', b'). ${ }^{20}$

Next, (40) is confirmed by the fact that while the on-PP exhibits a syntactic distribution distinct from the Japanese $n i / d e$-PP, the point made by Nishiyama (2005) and examined in section 3, $a$-words do behave similarly to the $n i / d e$-PP syntactically. To be specific, $a$-words can occur in all the syntactic contexts in (17) and also in indirect modification (e.g. (24a'), (26a')). In (17a) and indirect modification, the $n i / d e-\mathrm{PP}$ is a PlaceP/PredP, while the $n i$-PP in (17b) is a PlaceP/PredP licensed by AspP, i.e. a bounded PathP. Below, I present (i) data of $a$-words acting as morphological realizations of PlaceP/PredP and (ii) data of $a$-words representing a bounded PathP. In the following descriptions, I treat the underlined $a$-words in (39a) as deverbal.

\section{(I) $a$-words as PlaceP/PredP}

First, $a$-words can function as location-denoting adverbs, as the de/ni-PP in (15a) and (15bi). The prefix in this case expresses the meaning "in a location/position of." In Japanese, we saw that an active verb selects the de-PP while a stative verb selects the $n i$-PP. $A$-words, on the other hand, can be used both with an active verb, as in (45a), and with a stative verb, as in $(45 b)$ :

(45) a. active $\mathbf{V}+$ locative adverb

$1631 \mathrm{He}$ behaves himself ashore as if he were still on board.

BNC Claims for Accidents or Illness - At some point most of us travel, work or study abroad.

b. stative $\mathbf{V}$ (be, posture verbs) + locative adverb

1627 Then he astern sate down and governed. (= sat at the stern)

1762 The princess Henrietta was obliged to lie a-bed for want of a fire to warm her.

1823 I have now been two hours ashore.

1873 Fernando was afield against the Moors in what he called a holy war.

1876 The lights were out, and all were thought to be abed.

1905 Our coach will lock on when. . the clerks are aboard.

Next, similarly to the de-PP in (16a), $a$-words can be used as state-denoting adverbs or depictive phrases, the prefix expressing the meaning "in a state of."

(46) $a$-words as state-denoting (depictive) adverbs

a. $[\mathrm{a}-\mathrm{N}]$

c1300 Alle weore dryven athrang. [athrong "thronged, in a throng"]

1580 Till home they walk arowe. [arow "in a row"]

1600 Twelve lodgings of like stone, like height, were likewise built arew. [arow "in a row"]

b. $[\mathrm{a}-\mathrm{A}]$

1711 To be married I find is to be buried alive.

c. $[\mathrm{a}-\mathrm{V}]$ 
c1600 Your shallowest help will hold me up afloat.

$1815 \mathrm{He}$ commanded the force afloat.

1823 The tongs...were placed upright astraddle in front of the grate.

1855 Lattice-blinds all hanging askew.

1880 Nip these foolish fronds of hope a-sprout.

In (16bi), we saw that the $n i$-PlaceP/PredP functions as a manner-denoting adverb. $A$-words have this function as well:

(47) $a$-words as manner-denoting adverbs

a. $[\mathrm{a}-\mathrm{N}]$

1762 They take coach, which costs ninepence, or they may go afoot, which costs nothing.

1823 Swallows coming awing frae God knows where.

b. $[\mathrm{a}-\mathrm{A}]$

1769 The locks of the hair are flying abroad in all directions.

1767 One of the Company would often read aloud.

1838 I held my spoon awry, and soiled my clothes. ["obliquely, unevenly"]

1850 Those who think Awry, will scarce act straightly.

1843 The system is edited anew.

1862 Her prayer had been heard awrong!

c. $[\mathrm{a}-\mathrm{V}]$

1579 I am sure I cannot be lodged amiss in this house. ["erroneously"]

1821 The boy looking askew at him with his sharp gray eyes.

1833 Apt to see wrong, and speak amiss, and do the very reverse of what he ought to do. ["wrongly"]

In these cases, the prefix $a$ - denotes the meaning "in a manner of" as an instance of Pred. This view is confirmed by the fact that there is virtually no instance of $a$-words suffixed with $-l y$. The lack of manner adverbs in the form [ $a$-X-ly] makes a stark contrast with the abundance of directional adverbs in the form $[a-\mathrm{X}$-ward $]$. For example, compare the paradigm in (48a) with the one in (48b).

\section{[a-X]}

a. awide

anigh

adeep

acoy

athrong

b. away

agate

aback

adown

afore

amid

again

ahind/behind

a-west

anorth

a-south

\section{[a-X-suffix]}

[X-suffix]
widely
nighly
deeply
coyly
throngly
wayward(s)
gateward(s)
backward(s)
downward(s)
forward(s)
midward
gainward
hindward
westward(s)
northward
southward

The $[a-X]$ adverbs in (48a) are later replaced by the $[\mathrm{X}-l y]$ adverbs in the rightmost column. There is no instance in which the prefix and the suffix co-occur in the same adverb. This means that $a$ - and -ly are markers of the same function, i.e. they are allomorphs. In contrast, the $[a-\mathrm{X}]$ adverbs in $(48 \mathrm{~b})$ not only have the $[\mathrm{X}$-ward $(s)]$ counterpart but often also have the $[a-\mathrm{X}-\operatorname{ward}(s)]$ counterpart. In this case, the prefix and the suffix should be markers of different functions, either of which can be zero-marked.

In (45), (46), and (47), $a$-words function as adjuncts. They can be state-denoting predicative complements also; in (49), they function as complements of intransitive verbs and the copular be, while in (50) they function as complements of transitive verbs or small-clause predicates.

(49) $a$-words as state-denoting complements of intransitive verbs

a. $[\mathrm{a}-\mathrm{N}]$

1853 The two doctrines seem closely akin. 
$1863 \mathrm{He}$ was tired and adust with long riding.

b. $[\mathrm{a}-\mathrm{A}]$

1872 At night, the city is aflame with lamps.

1832 The baby in the cradle is for ever a-hungry, or a-thirsty.

1858 The Squire...told the men to look alive and get their job done.

c. $[\mathrm{a}-\mathrm{V}]$

1870 Before the sun of that day grew acold

1663 The soldiers...were all a-swim through the water that came in at the holes and leaks of the ship.

1783 The garrison stood aghast at this unforeseen disaster.

1855 No voluntary movement is sustained when we are asleep.

1866 Ephesus lies all abask in Mediterranean noonday.

1871 I was all aglow with the exercise.

1876 The sky was ablaze with a mighty mass of flame.

(50) $a$-words as state-denoting complements of transitive verbs

a. $[\mathrm{a}-\mathrm{N}]$

1792 Gentlemen we have ten of them agate today but two of them Spins very litle.

1869 We have had our sitting-room chimney afire this morning.

b. [a-A]

1837 They begin to think all religions alike.

c. $[\mathrm{a}-\mathrm{V}]$

1523 They helde the Englysshe archers well aworke all the day.

1714 Such a Consideration should be kept awake in us at all times.

1800 We want to have all our faculties awake.

1831 It is lucky...we have found our friends astir.

1869 I felt his lips and teeth ashake.

Although section 3 did not discuss this, the $d e / n i$-PP in Japanese can also function as predicative complements (Nishiyama 1999):

(51) a. Kabe-ga makka-de ar-u

Wall-Nom (very) red-Pred be-Pres

"The wall is red."

b. Watashi-wa John-o aware-ni omou.

I-Top John-Acc pathetic-Pred find

"I find John pathetic."

Finally, the following data indicate that a-words indirectly modify nominals with and without an e-place. As mentioned in section 3.2, English spatial PPs differ from Japanese de-PlaceP in their ability to modify nominals without an e-place.

(52) $a$-words as indirect modifiers

a. $[\mathrm{a}-\mathrm{N}]$

1737 A little House with trees a-row

1877 From the fluted spine atop, a plume Of horsehair waved.

1878 The number of gas-burners, lamps, or candles alight

BNC His life aboard was entirely idle ; the others waited on him like two wives , catering to his needs and bolstering his ego.

b. [a-A]

1896 Canary was the sole creature alive that could understand and feel with him.

BNC [...] unlike Valentin, she was never considered suitable for study abroad

BNC Havel's first journey abroad as President, to East and West Germany on Jan. 2 , represented a further break with tradition $[\ldots]^{21}$

c. $[\mathrm{a}-\mathrm{V}]$

1830 A shower of natural leaf-born flies a-swarm in the air

1878 A wilderness of sandy heath and dark-green common now all ablaze with gorse and broom

1879 The quantity of wheat afloat is still as much as $1,421,000$ qrs.

1986 Parklands and plains a-move with pasturing buffalo.

BNC But it was people who were the Institution's main asset and, linking progress afloat with that ashore Mr Vernon said. 


\section{(II) $a$-words as PathP}

In (15bii), the $n i$-PP expresses goal. In the context of a motion verb, $a$-words also express goal, as shown below, with the internal structure [Path TO [Pred $a$-[X]]]. Following (18), I assume that the covert TO is licensed by a motion verb, the goal-denoting $a$-words being selected as the complements of the verb.

\section{(53) $a$-words as goal-denoting complements}

a. [a-N]

1393 To telle How such goddess come aplace. ["come into this place"]

1610 Upon her breast Delight doth softly sleep, And of Eternal joy is brought abed.

1751 In harvest she rides afield in the waggon.

1777 The ships were drawn ashore.

1809 Some Carmen, as acamp they drove, Had seen her coursing for the western grove.

1961 Hardly anyone of the crew of six [etc.]...paid any attention to the man and teen-age boy who had come aboard.

b. [a-A]

1719 I resolv'd not to think of going Abroad any more, but to settle at Home.

1798 The roaring wind! it roar'd far off, It did not come anear.

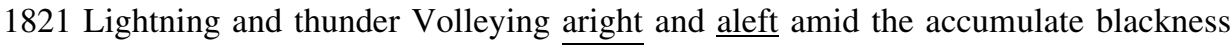

$1870 \mathrm{He}$ came anigher to the sun.

Also as we saw in (16bii) and (30b), the goal can be an abstract one. Similarly to the $n i$-PP in Japanese, $a$-words occur in intransitive change-of-state constructions (54a), causative constructions (54b), and resultative construction $(54 \mathrm{c})$.

(54) $a$-words as abstract-goal-denoting complements

a. Intransitive

$[\mathrm{a}-\mathrm{N}]$

1632 I my selfe grew all aflame.

1812 Swop! there a jumper falls aflat upon the ground.

1858 Far worse, the marriage itself went awry.

$1893 \mathrm{He}$ sometimes falls afoul of the night lines baited for eels. $[\mathrm{a}-\mathrm{V}]$

1865 Wilhelmina, faint, fasting, sleepless all night, fairly falls aswoon.

1879 His brown hair burst a-spread.

b. Causative constructions

[a-N]

1859 The helm of the George was instantly put a-lee.

1860 To set alight the devotion of the worshippers

1860 Any accident. . that puts an individual ajar with the world [a-A]

1751 All the sides and roof of the cabin is made of bark. . .bent round on the top, or set aflatt. $[\mathrm{a}-\mathrm{V}]$

1588 A Nurses Song of Lullabie, to bring her Babe asleepe.

1697 The jars of gen'rous wine...He set abroach, and for the feast prepar'd.

1748 They had immediately turned the canoe adrift.

1845 Like tears dried up with rugged huckaback, That sets the mournful visage all awrack.

1858 Scenes of cruelty and spoliation of which the recollection. . had still power enough to set his Scotch blood aboil.

1860 To set the tarnished gliding of the picture-frames... all a-glimmer.

1870 The rising water set everything awash.

1881 Then Jymul's supple fingers. . .Set athrill the saddest wire of all the six.

c. Resultative construction

[a-A]

$1994 \mathrm{Me}$, I'd as soon cut the whole thing aloose and see where it lights. [a-V]

c1640 By whispering winds soon lull'd asleep.

1653 When we have disputed and contended ourselves aweary 
1878 He throws himself all a-sprawl upon the ground.

1878 To cut myself adrift from my relatives

1912 If I had the backbone to go and get it I could drink my back teeth awash until I died.

For the sake of completeness, I cite below instances of the $n i$-PP occurring as the complement of an intransitive change-of-state verb and the complement of a causative verb:

$$
\begin{aligned}
& \text { a. Kao-ga makka-ni nat-ta } \\
& \text { Face-Nom red-Pred turn-Past } \\
& \text { "My face turned (very) red." } \\
& \text { b. John-ga kabe-o makka-ni si-ta } \\
& \text {-Nom wall-Acc red-Pred make-Past } \\
& \text { "John made the wall (very) red." }
\end{aligned}
$$

In the present analysis, the use of $a$-words in (53) and (54) is not due to the polysemy of the prefix $a$-, a view that would postulate the Pred $a$ - and the Path $a$-; rather, it is due to the working of the null TO. The view that $a$ - is not Path but Pred in (53) and (54) has two pieces of empirical evidence. First, as we saw in (48b), the goal Path head can be overtly realized by the suffix -ward, which leads to words of the parasynthetic structure $[a-\mathrm{X}$-ward]. Second, the source Path head is always realized by the overt preposition from in English (Svenonius 2010: sec. 3); hence, $a$-words are selected by from when the Path denotes source:

(56) 1894 At the close of the reign of Charles the Second, great part of the iron which was used in the country was imported from abroad.

To summarize this section, I have presented four pieces of evidence for (40), or the view that $a$ - is Pred. Given that the preposition on is spelled out at the head Loc in (8), the development from on to $a$ - embodies a distinct categorial change. This categorial change can be attributed to the working of grammaticalization because an item of a functional category turned into an item of a higher functional category.

Now that the development of $a$ - is identified as a case of grammaticalization, a brief mention to the view in (35) is in order. On the whole, this change is in accord with the semantic path in (35), spatial phrases turning into abstract statedenoting words. However, as far as the $a$-data are concerned, it remains unclear whether it is necessary to incorporate (35) as an ingredient of the grammaticalization process, for the semantic change arises as a result of the syntactic categorial change from Loc to $p /$ Pred. If the correspondence in $(23 \mathrm{~b})$ is a genuine equivalence, the relation between "space" and "quality" may be taken as a synchronic semantic extension rather than a diachronic change. ${ }^{22}$

\section{Deverbal $a$-words}

\subsection{The Emergence of a New Derivational Pattern}

In section 4, we saw that on-PPs underwent grammaticalization into morphological realizations of Place/PredP. This conclusion begs a question of why the prefix $a$ - can attach not only to $\mathrm{N}$ and A but also to $\mathrm{V}$, as shown in (39a-c). Given the correspondence in (23), $a$ - selecting $\mathrm{N}$ and $\mathrm{A}$ as its base is a natural consequence of the grammaticalization, but the structure in (8) offers no room for Pred to select $\mathrm{V}$ as its complement.

In my view, the answer to this question lies in the notion of construction as a diachronic development prompted by grammaticalization (e.g. Akimoto and Maeda 2013). More specifically, I propose the following developmental steps for $a$-words:

(57) a. On-phrases were grammaticalized into (i) $a$-words of the structure [Pred [A]] or (ii) $a$-words of the structure [Pred [ K [N]]].

(i) a-words of [Pred [A]]: e.g. (39b) alive, anew, aloud...

(ii) a-words of [Pred [ K [N]]: e.g. (39a) aboard, afield, afoot, asleep...

b. Those grammaticalized $a$-words gave rise to a productive word-formation pattern in which the prefix $a$ produces words of the complex syntactic category Pred+A with the meaning "in a state of."

the prefix $a$-: a marker of the derivational process $[\mathrm{X}] \rightarrow[$ Pred $+\mathrm{A}] \quad(\mathrm{X}=\mathrm{N}, \mathrm{A}, \mathrm{V})$

Denominal and de-adjectival $a$-words like (39a) and (39b) are direct results of the process in (57a). The upward category shift from $L o c$ to $p$ /Pred in (8) along with the gradual reduction of realization form led to $a$-words of the structure [Pred [A]], such as (39b), or those of the structure [Pred [ K [N]]], such as (39a). As discussed in section 3.2 (see (23) in particular), the combination of Pred and an NP/DP has the intervening category-shifting head K, so in the formation of a PlaceP/PredP, Pred always combines with an AP. As a result, denominal and de-adjectival $a$-words uniformly represent the complex syntactic category Pred $+\mathrm{A}$. 
Then, in the next step (57b), the denominal and de-adjectival $a$-words so formed gave rise to a productive derivational pattern in which the $a$-prefixation produces words of the complex category Pred + A (with the meaning "in a state of"). That is, the bound morpheme $a$ - was established as a derivational prefix that marks the following transpositional process (for Transposition, see Beard 1995):

$$
[\mathrm{X}] \rightarrow[\operatorname{Pred}+\mathrm{A}] \quad(\mathrm{X}=\mathrm{N}, \mathrm{A}, \mathrm{V})
$$

Because the pairing of the morpheme $a$ - and the process (58) is an instance of form-function pairing, the step in (57b) can be seen as a case of the emergence of a new construction as a result of grammaticalization.

In (58), as indicated by the arbitrary $\mathrm{X}$, any lexical category, not only $\mathrm{N}$ and $\mathrm{A}$ but also $\mathrm{V}$, can be the input category of the $a$-prefixation. Under the present analysis, the extension to $\mathrm{V}$ can be ascribed to the working of analogy, a rulegeneralizing mechanism often observed in the process of construction development. Of particular importance for the analogy is the pre-existence of $a$-words based on activity-denoting nouns such as those underlined in (39a):

(59) asleep, afloat, ablaze, aswoon, awane, awork, astrut, ahunt, astrain, abroach, aslant, aroar, atilt, adrift, ahold, adream

These words are old formations originally based on the phrase [on + deverbal noun] (e.g. on sleep). However, after the formal distinction between $\mathrm{N}$ and $\mathrm{V}$ was lost in $\mathrm{ME}, a$-words like (59) came to be analogically recognized as based on $\mathrm{V}$ (Jespersen 1942: 127-129). This analogy led to the development of the construction which accepts V as the input.

The two developmental steps in (57) are strongly supported by the sharp "age-divide" between denominal and deadjectival $a$-words in (39a, b) and deverbal $a$-words in (39c). As discussed above (39), the total of $327 a$-prefixed words collected from the $O E D$ include 181 denominal $a$-words, 38 de-adjectival $a$-words, and 88 deverbal $a$-words. Table 1 below shows their diachronic distribution; it classifies the denominal, de-adjectival, and deverbal $a$-words according to the period or century in which their first instances were attested.

Table 1. The number of denominal, de-adjectival, and deverbal $a$-words attested each century.

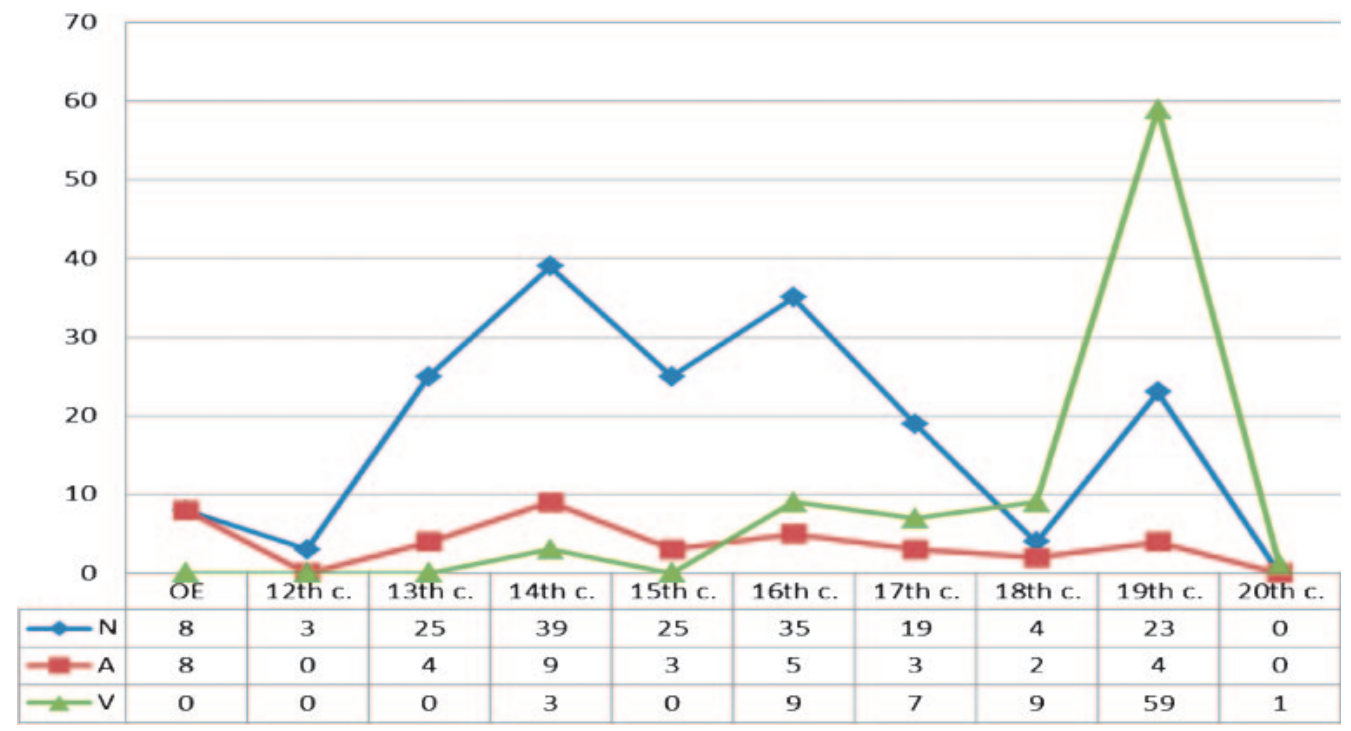

As this table clearly shows, the denominal and de-adjectival types had been attested since OE, with more than half of their instances (55\% for denominals and 63\% for deadjectivals) being formed in OE or ME, whereas the deverbal type became productive much later, most of their examples (95\% thereof) being attested in ModE. In fact, 67\% of all the deverbal instances are attested in the $19^{\text {th }}$ century. Jespersen (1942: 128) indicates the lingering productivity of the deverbal type in the $20^{\text {th }}$ century in his statement that " $[n]$ owadays such words $[a$-words] may be formed practically from any intransitive vb which is monosyllabic or else disyllabic ending in unstressed -le, $-r e$, or -en [...]" Denominal and de-adjectival types, on the other hand, are much less productive in ModE and virtually of zero productivity after the $20^{\text {th }}$ century.

In brief, this section has argued that the grammaticalization from on-phrases to $a$-words led to the emergence of a new construction that binds the form $a$-, the syntactic category Pred $+\mathrm{A}$, and the semantics "in a state of" together. 


\subsection{The Syntactic Category of $a$-words}

This final section examines the derivational process in (58), particularly focusing on its output category. (58) means that whatever the input category is, the output category of $a$-prefixation is Pred+A. ${ }^{23}$ The internal mechanism of this transposition can be captured by the VP $=$ PredP equivalence indicated in (3a, b). Concretely, my analysis of the affix $a$ - as Pred means that when the base $\mathrm{X}$ in (58) is A or N, it projects a PredP by the head-complement relation depicted in (3b). When the base $\mathrm{X}$ is V, it projects a PredP by mapping the VP structure in (3a) into (3b).

First, in section 4.2, we saw that $a$-words function both as adverbs (see (45), (46), (47)) and as predicative adjectives (see (49), (50), (53), (54)) in traditional parts-of-speech terms. Both of these functions can be subsumed under the output category Pred+A because in Baker's (2003) category theory, Adv is a type of A (Baker 2003: sec. 4.5; see also Sugioka and Lehr 1983 and Giegerich 2012 for a similar view). According to this view, adverbs are word-forms that A lexemes take in certain syntactic environments. Thus, if our discussion in section 4.2 is on the right track, English adjectives take the $-l y$ suffixed form (e.g. (48a) widely) when governed by Pred in the adjunct or complement position of VP. In a similar vein, adverbial and predicative adjectival $a$-words differ only in the syntactic positions of Pred+A; adverbial $a$-words are Pred $+\mathrm{A}$ in an adjunct position, while predicative adjectival $a$-words (and manner-type $a$ adverbials) are Pred $+\mathrm{A}$ in a complement position.

Second, Pred+A is a valid output category of a derivational process in view of the fact that "adjectives" in some languages always realize this complex category. According to Baker (2003: sec. 4.2.4), adjectives in some languages are required to be embedded under a Pred head as a kind of cross-linguistic parametric variation:

(60) In some languages, A must be in the minimal domain of a Pred (Slave, Ika, Japanese, etc.). (Baker 2003: 211)

As cited in the parenthesis in (60), Japanese adjectives are always of the complex type Pred+A (see Nishiyama 1999 for details), which leads to the difficulty of their functioning as direct modifiers, for example (Watanabe 2012). In word-formation, too, Japanese derives adjectives of the type Pred $+\mathrm{A}$; it seems to have no derivational affixes that derive the category A (without Pred), affixes similar to those deriving relational adjectives in European languages (e.g. $-e n$ and -ese in $(27 \mathrm{a}, \mathrm{b})$ ). Given the existence of the type of language as in (60), the complex category Pred+A qualifies as a valid syntactic category to be realized in a word form. Although English usually realizes Pred separately from A, either conflating it with the copular verb be or employing a covert morpheme for it, the grammaticalization processes in (57) have provided this language with the Japanese-type adjectival words.

Finally, as mentioned above, in Baker's (2003) analysis, Pred + AP is equivalent to V (unaccusative verb), as stated in (6a). This recognition is clearly shown by the parallelism between the structures in (3a) and (3b); an AP assigns the Theme role to its subject not by itself but with the help of Pred. Then, the output of the derivational process in (58) should be very close to unaccusative verbs, stative verbs in particular, given the meaning of the prefix $a$ - "in a state of."

Indeed, the prefix $a$-attaches to various verbs except stative verbs (*aknow, *aresemble) and achievement verbs $\left({ }^{*}\right.$ adie, ${ }^{*}$ anotice $) .{ }^{24}$ Witness the following classification of deverbal $a$-words based on their base verbs, in which the verb classes are taken from Levin (1993): $:^{25}$

\section{(61) Intransitive bases}

\section{a. Verbs involving the body}

Hiccup verbs: apant, aflush

Verbs of nonverbal expression: agape, agasp, aglare, asnort, agoggle, apout, asmirk

Verbs of gesture: awink, acock

Snooze verbs: asleep

Verbs of bodily state and damage to the body: atingle, astrain

Verbs of change of bodily state: aswoon

b. Verbs of emission

Verbs of light emission: aflicker, agleam, aglitter, aglow, ashine, aglimmer, asparkle, aflare, aglisten, aglint, ashimmer, ablaze

Verbs of sound emission: achatter, abeat, awhir, ajangle, amoan, amurmur, acry, aroar

Verbs of smell emission: areek

Verbs of substance emission: agush, aspout, asweat

c. Verbs of sounds made by animals: atwitter, acrow, ayelp

d. Verbs of existence

Exist verbs: alurk

Verbs of entity-specific modes of being: aflower, afoam, aripple, asmoulder, aspread, asprout, ablow, astream, ablow, aflow, aseethe, afizz.

Verbs of modes of being involving motion: adance, aflutter, aseethe, ashake, ashiver, asway, aswirl, athrob, atremble, awave, awobble, aquiver, asquirm

Verbs of group existence: aswarm, abristle 
Verbs of spatial configuration: astoop, asquat, astraddle, adangle, asprawl, aswing, aslant

Meander verbs: atumble

\section{e. Manner of motion verbs}

Roll verbs: awhirl, amove, adrift, afloat

Run verbs: astride, aswim, ajog, ascamper, astray, astrut

f. Verbs of searching: a-search, awatch,$^{26}$ ahunt

g. Intransitive verbs not classified in Levin (1993): , adream

(62) Transitive bases

a. Spray/load verbs: asmear

b. Wipe verbs: awash, asoak

c. Knead verbs: atwist

d. Hold verbs: $\underline{\text { ahold }}$

e. Psych-verbs: aweary, ajar, astir, athrill, atry

f. Destroy verbs: awreck, awaste

g. Cooking verbs: asimmer, aboil

h. transitive uses of verb types in (58a, b): aflush, acock, atilt

i. transitive verbs not classified in Levin (1993): astrand, adraw, agrime, ascent, awhet, abroach

As suggested by the description by Jespersen (1942: 128) cited in the previous section, $a$ - attaches to intransitive verbs productively. In particular, (61) reveals the strong preference of this prefix for intransitive (mainly unergative) verbs that conflate a manner component in their semantics. ${ }^{27}$ In these cases, (58) changes the base verb into an unaccusative-like predicate (Pred $+\mathrm{A}$ ) by focusing on or foregrounding the manner component of the base verb. Consequently, the $a$-words in (61) are semantically similar to and often paraphrased by the -ing participial adjectives from their base verbs; for example, $a$ sheep agasp vs. $a$ gasping sheep. Compare also the deverbal $a$-words in (52c) with the deverbal -ing modifiers in (63) below. The two deverbal forms seem to differ only in that the $a$-form always incorporates the Pred (; hence the contrast in (43)).

(63) a. 1784 Moisture and drought, mice, worms, and swarming flies

b. 1850 She... fixed a glance blazing with rage and scorn on the driver.

1855 A blazing sun upon a fierce August day

c. 1966 Two floating hotels. . .to carry tourists upstream from Cairo to Aswan

d. 1798 The moving Moon went up the sky, And nowhere did abide.

$A$-words in (61c) also speak for the unaccusative status of the output of (58) in that while their base verbs denote animals making specific sounds, $a$-words can denote the sound emission of an inanimate subject:

(64) a. 1833 Eaves all a-twitter with swallows

b. 1855 The Kennel's a-yelp

Compared to intransitive bases, $a$-words from transitive bases are fewer in number, as in (62). The data of this type, however, are significant in that they reveal the effects of the derivational process in (58) much more clearly than the $a$ words from intransitive verbs in (61). When $\mathrm{X}$ is a transitive (activity and accomplishment) verb, (58) changes it into a [Pred $+\mathrm{A}]$ predicate by suppressing its causative component ("small v" or the InitiationP in Ramchand 2008) and foregrounding its resultant state. As a result, $a$-words of this type are paraphrased by the -ed passive adjectival forms of their base verbs rather than the -ing adjectival form:

(65) a. 1861 All asmear with filth and fat

b. 1878 An ark, Sea-blown and a-wreck

c. 1872 The other man, a-grime With guilt

d. 1653 When we have $\overline{\text { disputd }}$ and contended ourselves aweary. $(=(54 \mathrm{c}))$

vs. We were totally $\left\{\right.$ wearied $/{ }^{*}$ wearying/cf. weary $\}$.

e. 1850 The body appears Hung awaste on the rock.

f. 1866 Snakes, with fangs a-whet vs. all $\left\{\right.$ smeared $/{ }^{*}$ smearing $\}$ with filth and fat

vs. a $\left\{\right.$ wrecked $/{ }^{*}$ wrecking $\}$ ark

vs. \{grimed $/{ }^{*}$ griming $\}$ with guilt

vs. hung $\left\{\right.$ wasted $/{ }^{*}$ wasting $\}$ on the rock

vs. with fangs $\left\{\right.$ whetted $/{ }^{*}$ whetting $\}$

In brief, because $a$-words have the category Pred+A (and express the meaning "in a state of"), the prefix $a$-functions like the active participial suffix -ing with respect to intransitive bases but like the passive participial suffix -ed with respect to transitive bases.

The working of the category-changing process in (58) and the unaccusative-like status of its output are also evident with $a$-words from the "run" type of manner of motion verbs in (61e). This type of motion verbs express a 
volitional movement of an agentive subject, but when attached with $a$-, they become closer to the "roll" type of motion verb, expressing the continuation of a non-volitional movement. For example, compare the following two sentences:

(66) a. 1870 The shallow flowing sea...set the wrack a-swim.

b. One can no longer go a-swimming in the lake, to be sure, but there is the natatorium with its mammoth tank containing thousands of gallons of water. Boating, too, is no more, but for compensation there is glorious skating for steel-shod...

(taken from University of Notre Dame Archives: http://archives.nd.edu/research/texts/seminarian.htm)

(66b) is an instance of the go $+a$-Ving purpose construction discussed in section 4.1 (see the examples in (38d)). Because this $a$ - is a clitic, attaching to an -ing verbal noun and scoping over the whole NP, the phrase $a$-swimming (in the lake) expresses a volitional activity of the agentive subject one; if not, this phrase could not occur in the purposedenoting construction. On the other hand, a-swim in (66a) expresses a nonvolitional movement of an inanimate object because this $a$ - is a derivational suffix that changes its base into an unaccusative-like predicate of the category Pred + A.

To sum up, section 5 has shown that deverbal $a$-words are productively formed by the derivational pattern (58), a construction which emerged from denominal and de-adjectival $a$-words grammaticalized from on-PPs. When $\mathrm{X}=\mathrm{V}$, (58) changes the event structure of the input verb so as to fit the output category Pred $+\mathrm{A}$.

\section{Concluding Remarks}

By linking Baker's (2003) theory of syntactic categories and Svenonius' (2006, 2010) multi-layer analysis of spatial PPs, this paper has shed light on the following three questions: (i) how the prefix developed from the preposition specifically, (ii) why a prefix so derived can exhibit non-canonical properties, and (iii) whether (and in what way) the development can be viewed as a case of grammaticalization. For the first question, I have shown that the formal change from the preposition through the clitic stage to the prefix goes hand in hand with the categorial change from Loc to $p /$ Pred. For the second question, I have argued that the status of the prefix $a$ - as Pred and the category of $a$-words as Pred + A account for the peculiar properties of $a$-words, which are shared by Japanese adjectives rather than by English canonical adjectives. Finally, I answered the third question in affirmative, showing that the development from on to $a$ - is a valid instance of grammaticalization in terms of its formal and categorial changes and also in its further development into a new construction.

I close this paper by pointing out two future research questions. The first question concerns the fact that some $a$-words have acquired a prepositional function, as in: ${ }^{28}$

(67) 1578 Aloft their shirts they weare a garment iocket wise.

1642 They came hard aboard the shore.

1728 The cardinal. . .continues. . .to fright the clergy...from coming a-near me.

I list below $a$-words that allow a prepositional use according to the $O E D$ :

(68) about, adown, again, along, afore, amid, adownward, above, aforeward, aloft, across, anovenon, around, atour, alength, aside, amidst, afront, aboard, aslant, abaft, alow, atween, abreast, athwart, ahead, aloof, a-weather, astride, anear, ahind, acrost, anigh

As this list indicates, the prepositional use tends to be found in $a$-words formed in OE or ME. Although this paper has investigated the development of $a$-words as a type, a token-level research is necessary in order to reveal the process in which a strongly grammaticalized $a$-word acquires the prepositional usage (cf. Waters 2009).

Secondly, my analysis of $a$ - will receive stronger confirmation if there are other morphemes with a similar property. As far as I have noticed, off and mid(-) seem to be able to produce predicative adjectives of the category Pred + A. Offwords functioning as the PlaceP or PathP, such as $(69 \mathrm{a}, \mathrm{b})$, are recorded in dictionaries. Mid-words with these functions seem to be in the process of rising from the $\underline{i n}$ mid- $N$ phrase; their instances abound in the Internet, as in (70), but have not been listed in a dictionary yet.

(69) a. go off-shore, go off-island, walk offstage [onstage], throw [knock, push] him off-balance

b. 1921 We strain to hold the thought that, off-stage, you [sc. Marjorie Rambeau] Are happy as the widelymentioned lark.

1933 A player with a distinctive and adenoidal voice...made his first speech off-stage.

1895 The dab travels in any direction, offshore or inshore, or along the coast.

1999 Don't go out at all if the wind is blowing offshore. 
(70) a. There is nothing that frustrates me more than the moment when you are mid conversation with other adults and some says "Kids these days," assuming everybody will nod in agreement $[\ldots]$ (http://hopefullearning.wordpress.com/category/restorative-justice/)

b. Don't switch hats mid-conversation. (http://staff.kings.edu/jkmoore/senior\%20seminar/ethicalblogger.pdf)

c. I absolutely hate it when people leave mid conversation and don't even say BRB or bye. (http://www.wattpad.com/18015761-what-grinds-my-gears-messaging-etiquette)

Although it is clear that off and mid(-) originate from spatial P elements (i.e. the particle off and the Axial Part middle), a careful research is necessary to reveal how such elements can develop the $p /$ Pred function.

\section{Acknowledgments}

I am deeply indebted to Hiroyuki Nawata, Fumikazu Niinuma, Yoshiki Ogawa, and Masaharu Shimada for their comments on the topic. I am grateful to Yoshiki Ogawa for informing me of recent PP studies including Svenonius (2006), Takamine (2006), Collins (2007), Waters (2009), and Booij (2010: ch.6). Thanks also go to the audience at the 2013 ELSJ workshop "Grammaticalization, lexicalization, and cartography: Interface between syntax and morphology," where a part of this study was presented. For the revision of the manuscript of this paper, I have greatly benefitted from the informative and detailed comments from Yoshiki Oagawa and two anonymous referees. Of course, I am solely responsible for the content of this paper. The research for this study was conducted under the financial support of Tohoku University (Tohoku Leading Women's Jump Up Project 2013) and the Japanese Ministry of Education, Culture, Sports, Science, and Technology (Grant-in-Aid (c), No. 24520417).

\section{Notes}

${ }^{1}$ For the denominal verb type (e.g. uncage), see Nagano (2011).

${ }^{2}$ Of course, there are some simple or non-derived adjectives that indirectly modify a noun in the post-nominal position (e.g. the editor present), but they also allow a direct modifier use in the prenominal position (e.g. the present editor).

${ }^{3}$ As will be evident in section 3, I follow Baker for the analysis of the constructions (i) and (ii), but for (iii), I do not adopt his view of the resultative predicate as AP. Following Nishiyama (2005), I will treat it as governed by Pred.

${ }^{4}$ Based on cross-linguistic data, Baker distinguishes the NP-selecting Pred, Pred ${ }_{N}$, and the AP-selecting Pred, Pred ${ }_{A}$. The fact that some languages (e.g. Vata, Tamil) systematically disallow adjectival predication suggests a parameter variation on the occurrence or working of $\operatorname{Pred}_{\mathrm{A}}$. In contrast, all languages seem to have Pred $\mathrm{N}_{\mathrm{N}}$, given that all languages permit predicate nominals of some kind (Baker 2003: 210).

${ }^{5}$ Svenonius (2010: 134) positions behind in AxP, in contrast to Svenonius (2006: 52-53), where he puts it in the position equivalent to Loc in (8).

${ }^{6}$ According to Waters (2009), the category AxPart is relatively open and accepts a variety of words, not limited to nominals. She shows how this property has been driving the "preposition cycle" in the history of English.

${ }^{7}$ The structure in (11) is based on the structure (23) and the descriptions thereof in Svenonius' (2006: 59).

${ }^{8}$ Ayano (2005: 15) also notes that "prepositions can only be [+directional] when selected by unaccusative motion verbs." Collins (2007: 24) takes the position that "a directional PP headed by 'to' (covert or overt) is always the complement of a verb," so he posits the null verb GO for the restrictive nominal modification by a directional PP (e.g. $a$ path toJohn'shouse, a path (*to) home).

${ }^{9}$ The comments and questions from Yoshiki Ogawa and the two anonymous referees were particularly helpful in revising this section. I have also benefitted from the discussions with Yoshiki Ogawa and Masaharu Shimada on the relevant Japanese data.

10 The data in (15) and (16) are taken from Nishiyama (2005: 145, 149, 151). I specified the gloss for $n i$ in (15bii) in accordance with his final analysis. Also, Nishiyama does not explicitly mention the AP status of the complement phrase in (16). I will discuss this issue below.

${ }^{11}$ The PlaceP at home, for example, is an adjunct in cases like (i) but obligatory in cases like (ii):

(i) They stayed (at home). While he sat (at home) feeling guilty.

(ii) He was *(at home). With John*(at home)... I need him*(at home) early. (Collins 2007: 23)

${ }^{12}$ An anonymous referee has pointed out the possibility that $n i$ and $d e$ as spatial postpositions be generated in the Loc head in (11), similarly to in and on. In view of the historical fact that the adjunct AT used to be realized by the morphologically complex form nite, which includes the morpheme $n i$ (Yoshiki Ogawa, p.c.), the suggestion points to the following PlaceP structure in which $n i$ occurs in Loc:

(i) [PlaceP [LocP [DP ] Loc ] AT ]

a. $\quad$ ni $0 /$ te

b. $\quad$ ni/te (de)

The idea is that $n i$ was base generated in Loc in older times, as in (ia). The AT head was overtly realized by te only 
when the PlaceP is an adjunct; otherwise, it was zero-marked. Pursuing this idea, we could say that the modern use of $n i$, an allomorphe of AT, resulted from the same Loc-to-AT grammaticalization as the English prefix $a$ - (see section 4). As indicated in (ib), due to this grammaticalization, $n i$ and te went into a paradigmatic relationship and te underwent voicing into $d e$.

13 Takamine (2006) also argues that the Japanese spatial PP has the internal structure in (11), with the postposition $n i$ realizing the AT (Place) head.

${ }^{14}$ If I am not mistaken, the reason why Baker and Nishiyama prioritize different P categories must have much to do with the different adjectival conflation patterns in the languages they each are most familiar with. The category A conflates with Pred in Japanese (Nishiyama 1999), but it does not in many of the Indo-European languages (Nagano and Shimada 2013).

${ }^{15}$ I assume that the no following the postposition de in (24a') is a morphological linker for an indirect modifier without a tense morpheme (Kitagawa and Ross 1982).

${ }^{16}$ I have consulted both the $O E D 2^{\text {nd }}$ edition CD-ROM version and the on-line version.

${ }^{17} \mathrm{Cf}$. Kume (2009) for the development of the purpose construction in the form go/come + VP (e.g., They come talk to me every day).

${ }^{18}$ As will become clear below, the hyphen is used, though less frequently, in the prefix stage as well. Although further research is necessary, I take this fact as a reflection of the gradual process in which the clitic turns into the prefix $a$-.

19 The affix vs. clitic distinction in terms of scope is a matter of debate, though (Spencer and Luís 2012: sec. 7.3.3). For example, Yoshiki Ogawa has pointed out that some prefixes can take wide scope over the phrase outside its base (e.g. The answer was \{uncertain to anyone/ * certain to anyone\}). Spencer and Luís (2012: 218) claim that "linguistic theory shouldn't actually draw a clear distinction between clitics and affixes."

${ }^{20}$ An anonymous referee has provided me with the following example from the Internet:

(i) but we never notice it because the people around us are as asleep as we are. Cf. (44b)

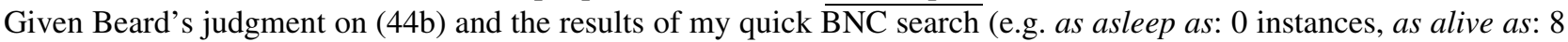
instances, as afloat as: 0 instances; more asleep: 2 instances, more alive: 27 instances, more afloat: 0 instances), I think that the licensing of the degree expression in (i) should be attributed to token-level or lexical properties of asleep.

In fact, Beard might want to change the choice of $a$-words in (44a, b) because asleep and alive are not prototypical $a$ words. As noted by Quirk et al. (1985: 408-409), asleep and alive are exceptional as $a$-words, occurring in the comlement of the verb seem without the copular be (e.g. The patient seemed asleep). The instance in (i) supports this view. According to the $O E D$, asleep and alive have opposite gradable meanings defined by the same scale of 'activeness': alive "full of energy, active" and asleep "dormant, inactive, idle." The logical conclusion seems to be that alive and asleep are A or are polysemous between A and Pred+A. I suggest that the A usage of these two words has much to do with their being among the oldest $a$-words attested in the OED. Their $a$ - might still be at Loc, representing the starting point of the Loc-to- $p$ grammaticalization.

21 This example shows that $a$-words can modify a nominal (with an e-place) in the Path interpretation. The following contrast indicates that the modification by a PathP is restricted to e-place nominals even in English:

(i) a. the boat to Narvik, the tracks into the cave, the path up to the summit

b. *The cat to the edge was incautious.

*The butter onto the knife was soft.

(Svenonius 2010: 144-145)

22 As for the path space > time in (35), we have the clitic and prefix $a$-words denoting time: (38d) and (39a ii). As a more systematic change, the be on/a-Ving construction in (37c i) (38c i) provided one of the source constructions for the progressive construction. Discussing a similar development from a locative construction to a progressive one in Dutch, Booij (2010: ch.6) suggests the view that (35) represents both a cognitive metaphorical process and a grammaticalization process.

23 The notion of output-oriented word formation rule advocated by Plag (2004) would be very helpful to make sense of the format and nature of the process in (58).

24 This selectional property clearly distinguishes the prefix $a$-from the clitic $a$, which can attach to the -ing form of achievement verbs:

(i) 1732 I was told that one was a-dying. . little more than a stone-cast from the church.

1842 An old widower that's ben a-marrying of a young girl. $\quad(=(38 \mathrm{~d} i))$

This is possible because a clitic does not change the category of its complement; $a$ - in (i) syntactically relates its NP complement to the main verb. On the other hand, the prefix $a$-cannot attach to achievement (and stative) verbs because it turns its complement word into a stative predicate of the category Pred $+\mathrm{A}$.

25 The underlined $a$-words belong to (59), $a$-words which are etymologically denominal but synchronically deverbal.

26 These $a$-words are based on the uses of search and watch taking the preposition for:

(i) 1920 For whom...we must be still a-search.

1856 As a dog a-watch for his master's foot

${ }^{27}$ For the unergative vs. unaccusative status of verbs of emission, I follow Potashnik's (2012) unergative analysis. First, they produce -er nominals (e.g. beeper, buzzer, clicker; Potashnik 2012: 252). Second, the OED paraphrases the $a$ words in (61b) via adjectival passives in -ing rather than -en (e.g. aflicker "flickering," agleam "gleaming," achatter 
"that makes a chattering noise," awhir "whirring," agush "gushing"). I thank one of the referees for generously informing me on this point.

${ }^{28}$ I owe this observation to Yoshiki Ogawa.

\section{REFERENCES}

[1] Ackema, Peter and Ad Neeleman (2004) Beyond Morphology: Interface Conditions on Word Formation, Oxford University Press, Oxford.

[2] Akimoto, Minoji and Mitsuru Maeda (eds.) (2013) Bunpooka to Koobunka (Grammaticalization and constructionalization), Hituzi, Tokyo.

[3] Ayano, Seiki (2005) "The Layered Internal Structure of Spatial PPs," Adpositions of Movement, ed. by Hubert Cuyckens, Water de Mulder and Tanja Mortelmans, 3-27, John Benjamins, Amsterdam.

[4] Baker, Mark C. (1985) "The Mirror Principle and Morphosyntactic Explanation," Linguistic Inquiry 16, 373-416.

[5] Baker, Mark C. (1988) Incorporation: A Theory of Grammatical Function Changing, The University of Chicago Press, Chicago.

[6] Baker, Mark C. (2003) Lexical Categories: Verbs, Nouns, and Adjectives, Cambridge University Press, Cambridge.

[7] Beard, Robert (1995) Lexeme-Morpheme Base Morphology: A General Theory of Inflection and Word Formation, State University of New York Press, Albany.

[8] Bolinger, Dwight (1967) "Adjectives in English: Attribution and Predication," Lingua 18, 1-34.

[9] Booij, Geert (2010) Construction Morphology, Oxford University Press, Oxford.

[10] Bowers, John (1993) “The Syntax of Predication,” Linguistic Inquiry 24, 591-656.

[11] Cinque, Guglielmo (2010a) The Syntax of Adjectives: A Comparative Study, MIT Press, Cambridge, MA.

[12] Cinque, Guglielmo (2010b) "Mapping Spatial PPs: An Introduction," in Cinque and Rizzi (eds.), 3-25.

[13] Cinque, Guglielmo and Luigi Rizzi (eds.) (2010) Mapping Spatial PPs: The Cartography of Syntactic Structures, Oxford University Press, Oxford.

[14] Collins, Chris (2007) "Home Sweet Home," New York University Working Papers in Linguistics 1, 1-33.

[15] Giegerich, Heinz J. (2012) "The Morphology of -ly and the Categorial Status of 'Adverbs' in English," English Language and Linguistics 16:3, 341-359.

[16] Grimshaw, Jane (1991) "Extended Projection,” ms., Brandeis University.

[17] Heine, Bernard, Ulrike Claudi and Friederike Hünnemeyer (1991) Grammaticalization: A Conceptual Framework, The University of Chicago Press, Chicago.

[18] Hopper, Paul J. and Elizabeth Closs Traugott (2003) Grammaticalization, $2^{\text {nd }}$ ed., Cambridge University Press, Cambridge.

[19] Ito, Takane and Yoko Sugioka (2002) Go no Sikumi to Gokeisei (Morphology and word-formation), Kenkyusha, Tokyo.

[20] Jackendoff, Ray (1987) "The Status of Thematic Relations in Linguistic Theory," Linguistic Inquiry 18, 369-411.

[21] Jackendoff, Ray (1990) Semantic Structures, MIT Press, Cambridge, MA.

[22] Jespersen, Otto (1942) A Modern English Grammar on Historical Principles, Part VI: Morphology, Ejnar Munksgaard, Copenhagen.

[23] Kastovsky, Dieter (1986) "Problems in the Morphological Analysis of Complex Lexical Items," Acta Linguistica Academiae Scientiarum Hungaricae, Tomus 36, 93-107.

[24] Kastovsky, Dieter (1992) "Semantics and Vocabulary," The Cambridge History of the English Language, vol. 1, ed. by Richard M. Hogg, 290-408, Cambridge University Press, Cambridge.

[25] Kitagawa, Chisato and Ross, Claudia N. G. (1982) "Prenominal Modification in Chinese and Japanese," Linguistic Analysis 9 , 19-53.

[26] Koma, Osamu (1998) "Verbal Gerund and Its Historical Development in English," English Historical Linguistics and Philology in Japan, ed. by Jacek Fisiak and Akio Oizumi, 153-170, Mouton de Gruyter, Berlin.

[27] Koma, Osamu (2000) Eigoshi ni okeru haseimeisi no kijyutsutekikenkyuu (A descriptive study of nominalizations in Old English), Final report of the research based on the Grant-in-Aid (c), No. 10610462, Tokyo Gakugei University.

[28] Kratzer, Angelika (1996) "Severing the External Argument from the Verb," Phrase Structure and the Lexicon, ed. by Johann Rooryck and Laurie Zaring, 109-137, Kluwer, Dordrecht.

[29] Kume, Yusuke (2009) "On Double Verb Constructions in English: With Special Reference to Grammaticalization," English Linguistics 26:1, 132-149.

[30] Lehmann, Christian (1985) "Grammaticalization: Synchronic Variation and Diachronic Change," Lingua e Stile 20, $303-318$.

[31] Levin, Beth (1993) English Verb Classes and Alternations: A Preliminary Investigation, The University of Chicago Press, Chicago.

[32] Marchand, Hans (1969) The Categories and Types of Present-Day English Word-Formation: A Synchronic-Diachronic Approach, $2^{\text {nd }}$ ed., C. H. Beck, Munich.

[33] Marcus, Manfred (1998) "A-adjectives (asleep etc.) in Postnominal Position: Etymology as a Cause of Word Order (Corpusbased)," Explorations in Corpus Linguistics: Proceedings of the $18^{\text {th }}$ International ICAME Conference in Chester, 22-26 May 1997, ed. by Antoinette Renouf, 135-146, Rodopi, Amsterdam.

[34] McNulty, Elaine (1988) The Syntax of Adjunct Predicates, Ph. D. dissertation, University of Connecticut.

[35] Nagano, Akiko (2011) "The Right-Headedness of Morphology and the Status and Development of Category-Determining Prefixes in English," English Language and Linguistics 15, 61-83.

[36] Nagano, Akiko (2013a) "Derivational Prefix be- in Modern English: The Oxford English Dictionary and Word-Formation Theory," English Studies 94, 448-467.

[37] Nagano, Akiko (2013b) "Morphology of Direct Modification," English Linguistics 30, 111-150.

[38] Nagano, Akiko and Masaharu Shimada (2013) "Relational Adjectives (RAs) in Japanese and the RA vs. PP debate," a paper 
presented at the 9th Mediterranean Morphology Meeting, September 16, 2013, Dubrovnik.

[39] Nakao, Toshio (1972) Eigoshi II (The history of English, vol. 2), Taishukan, Tokyo.

[40] Namiki, Takayasu (1985) Gokeisei (Word formation), Taishukan, Tokyo.

[41] Nevalainen, Nevalainen, Terttu (1999) "Early Modern English Lexis and Semantics," The Cambridge History of the English Language, vol. 3, ed. by Roger Lass, 332-458, Cambridge University Press, Cambridge.

[42] Nishiyama, Kunio (1999) “Adjectives and the Copulas in Japanese," Journal of East Asian Linguistics 8, 183-222.

[43] Nishiyama, Kunio (2005) "Verbs, Adjectives and Pred: Review of Mark C. Baker, Lexical Categories," English Linguistics 22, 133-161.

[44] Noonan, Máire (2010) "Á to Zu," In Cinque and Rizzi (eds.), 161-195.

[45] Ogawa, Yoshiki (2001) “The Stage/Individual Distinction and (In)alienable Possession," Language 77, 1-25.

[46] Ogawa, Yoshiki and Fumikazu Niinuma (2013) "On the Syntactic Licensing of Locative Expressions in Japanese," Proceedings of Glow in Asia IX 2012: The Main Session, ed. by Nobu Goto, Koichi Otaki, Atsushi Sato and Kensuke Takita, 229-244.

[47] Plag, Ingo (2004) "Syntactic Category Information and the Semantics of Derivational Morphological Rules," Folia Linguistica 38, 193-225.

[48] Potashnik, Joseph (2012) "Emission Verbs," The Theta System: Argument Structure at the Interface, ed. by Martin Everaert, Marijana Marelj, and Tal Siloni, 251-278, Oxford University Press, Oxford.

[49] Quirk, Randolph, Sidney Greenbaum, Geoffrey Leech and Jan Svartvik (1985) A Comprehensive Grammar of the English Language, Longman, London.

[50] Ramchand, Gillian Catriona (2008) Verb Meaning and the Lexicon: A First-Phase Syntax, Cambridge University Press, Cambridge.

[51] Roberts, Ian and Anna Roussou (2003) Syntactic Change, Cambridge University Press, Cambridge.

[52] Rothstein, Susan (1983) Syntactic Forms of Predication, Ph. D. dissertation, MIT.

[53] Sadler, Louisa and Douglas J. Arnold (1994) "Prenominal Adjectives and the Phrasal/Lexical Distinction," Journal of Linguistics 30, 187-226.

[54] Spencer, Andrew and Ana R. Luís (2012) Clitics: An Introduction, Cambridge University Press, Cambridge.

[55] Sproat, Richard and Chinlin Shih (1988) "Prenominal Adjectival Ordering in English and Mandarin," NELS 18, 465-489.

[56] Sugioka, Yoko and Rachel Lehr (1983) "Adverbial -ly as an Inflectional Affix," CLS 19, 293-300.

[57] Svenonius, Peter (2006) "The Emergence of Axial Parts," Nordlyd: Troms $\phi$ Working Papers on Language \& Linguistics 33, 49-77.

[58] Svenonius, Peter (2010) “Spatial P in English," In Cinque and Rizzi (eds.), 127-160.

[59] Tajima, Matsuji (1985) The Syntactic Development of the Gerund in Middle English, Nan'undo, Tokyo.

[60] Takamine, Kaori (2006) “Axial Part Phrase in Japanese,” Nordlyd: Troms $\phi$ Working Papers on Language \& Linguistics 33, 78-97.

[61] Traugott, Elizabeth Closs (2010) "Grammaticalization," The Contiuum Companion to Historical Linguistics, ed. by Silvia Luraghi and Vit Bubenik, 269-283, Continuum, London.

[62] Visser, Frederikus Theodorus (1966) An Historical Syntax of the English Language: Part II, E. J. Brill, Leiden.

[63] Watanabe, Akira (2012) "Direct Modification in Japanese," Linguistic Inquiry 43, 504-513.

[64] Waters, Cathleen (2009) "The Preposition Cycle in English," Cyclical Change, ed. by Elly van Gelderen, 285-330, John Benjamins, Amsterdam.

[65] Williams, Edwin (1981) “On the Notions 'Lexically Related' and 'Head of Word'," Linguistic Inquiry 12, 245-274.

[66] Wunderlich, Dieter (1991) "How do Prepositional Phrases Fit into Compositional Syntax and Semantics?” Linguistics 29, 591-621.

[67] Yokogoshi, Azusa (2005) "On the Structural Change of Small Clauses: With Special Reference to the Distribution of as and for,” English Linguistics 22:1, 82-102.

[68] Zandvoort, Reinard Willem (1969) A Handbook of English Grammar, $5^{\text {th }}$ ed., Longmans, Green and Co., London.

[69] Zwart, Joost (1997) "Vectors as Relative Positions: A Compositional Semantics of Modified PPs," Journal of Semantics 14, 57-86. 